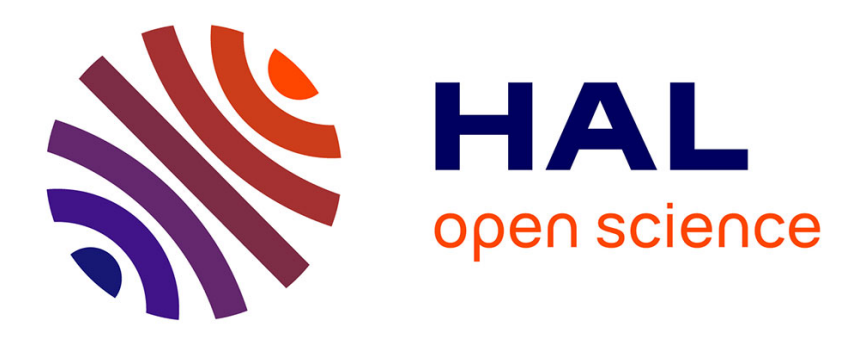

\title{
Extracting Information from the Market to Price the Weather Derivatives
}

\author{
Hélène Hamisultane
}

\section{To cite this version:}

Hélène Hamisultane. Extracting Information from the Market to Price the Weather Derivatives. 2007. halshs-00079192v2

\section{HAL Id: halshs-00079192 \\ https://shs.hal.science/halshs-00079192v2}

Preprint submitted on 14 Oct 2007

HAL is a multi-disciplinary open access archive for the deposit and dissemination of scientific research documents, whether they are published or not. The documents may come from teaching and research institutions in France or abroad, or from public or private research centers.
L'archive ouverte pluridisciplinaire HAL, est destinée au dépôt et à la diffusion de documents scientifiques de niveau recherche, publiés ou non, émanant des établissements d'enseignement et de recherche français ou étrangers, des laboratoires publics ou privés. 


\title{
Extracting Information from the Market to Price the Weather Derivatives
}

\author{
Hélène Hamisultane ${ }^{\dagger^{*}}$
}

November 12, 2006

\begin{abstract}
Weather derivatives were first launched in 1996 in the United-States to allow companies to protect themselves against weather fluctuations. Even now their valuation still remains tricky. Because their underlying is not a traded asset, they cannot be priced by using the Black and Scholes formula. The market is said to be incomplete for the weather derivatives. Other pricing methods were proposed but they cannot be calibrated to the market since there are no available weather option prices. However, quoted prices exist for the weather futures. To our knowledge, no empirical study has been conducted to extract information from these prices to value the weather options. It is perhaps because weather futures markets are mainly illiquid. It is observed that some contracts like the Chicago, London and New York ones are traded frequently. So the purpose of this paper is to carry out this empirical study based on the New York futures prices. Two types of information are extracted : the risk-neutral distribution and the market price of weather risk. We propose to infer the first one with the optimization problem suggested by Jackwerth and Rubinstein (1996) for which we will use Monte-Carlo simulations. The second one is recovered by solving numerically a partial differential equation (PDE) with the finite difference method in the optimization problem as shown by Pirrong and Jermakyan (2001). Both information are then used to value the New York futures and option. We compare these prices as well as the two approaches employed here. We also infer information from other weather contracts to price the New York weather derivatives.
\end{abstract}

Keywords : weather derivatives, incomplete market, mean-reverting jump diffusion process, EGARCH process, PIDE, inversion problem

\footnotetext{
† EconomiX , 200 avenue de la République, 92000 Nanterre, France. E-mail : helene.hamisultane@free.fr

* I would like to thank Sandrine Lardic and the anonymous referee of the AFFI conference for their useful comments.
} 


\section{Introduction}

Weather derivatives took place in the United-States in 1996 after the deregulation of the energy market and were jump traded during winter of 1997-98 due to El Niño. This is a warm current which was responsible of weather anomalies in South and North America. North America had a warmer winter than normal while South America was wetter than normal. Weather derivatives were launched to allow the companies to hedge against risk of weather fluctuations. They allow also investors to diversify their portfolio since these contracts are not correlated with the financial assets. But these contracts are not easy to price. Black and Scholes formula cannot be used to value them because their underlying is not a traded asset. Since the payoff of the weather derivatives is similar to the payoff of the Asian derivatives, the price of such contracts does not have a closed-form expression. Therefore, pricing methods like the Monte-Carlo approach (Alaton, Djehiche and Stillberger (2002)) and the resolution of a partial differential equation (Brody, Syroka and Zervos (2002) and Harris (2003)) were proposed to price the weather derivatives. But all these methods require the estimate of the market price of weather risk because the market is incomplete. This unobservable parameter must be inferred from the weather option prices but these latters are not available since the weather options are traded only over-the-counter. In practice, weather derivatives are priced by using the actuarial method. Their value corresponds to the expected outcome under the historical probability plus a charge depending on a risk measure which is usually the standard deviation (Brix, Jewson and Ziehmann (2002), Jewson (2004a), Marteau, Carle, Fourneaux, Holz and Moréno (2004)). This method has led to numerous empirical studies concerning the temperature modelling (Moréno (2000), Brix et al.(2002), Roustant (2002), Jewson (2004b)). However, quoted weather futures prices are available and it seems to us that no empirical study relative to them has been carried out until now. We think that this is because the weather futures market is illiquid. Recently, it is observed that some contracts are frequently traded on the Chicago Mercantile Exchange (CME) like the Chicago, London and New York contracts (Jewson (2004a)). Thus we propose to use information contained in the New York futures prices to value the New York weather option. Our study focuses on the temperature-based contracts, especially on the cooling degree day contracts, since all CME contracts are based on the temperature index. We are interested in inferring the risk-neutral distribution from the prices by using the Monte-Carlo simulations and the optimization problem suggested by Jackwerth and Rubinstein (1996). We also want to estimate and to compare prices derived from the extraction of the market price of weather risk which requires the resolution of an optimization problem and of a partial differential equation. Following Pirrong and Jermakyan (2001), we solve numerically the PDE by using the finite difference method. We compare the estimated prices as well as the methods used to infer both information. We also show that the New York weather contracts can be valued by using information implied from other weather contracts which the index is correlated with the New York one. The whole prices are computed by using a mean-reverting jump-EGARCH diffusion process for the New York daily average temperature since we show that the temperature is not normally distributed and exhibits a time-varying volatility. The structure of this paper is organized as follows. In section 2, we describe the weather derivatives. Section 3 is devoted to the estimation of the temperature process. Section 4 deals with the notion of risk-neutral density in the incomplete market setting. In section 5, we simulate the temperature process and solve an unconstrained optimization problem to extract the riskneutral distribution which will be used to price and to forecast the New York weather futures and option values. Section 6 concerns the extraction of the market prices of weather risk from the New York weather futures as well as from the Philadelphia weather futures. We show in that section that the weather derivatives can be priced by using information from other 
weather contracts which the index is correlated with the underlying of the contract we want to price.

\section{Basics about the weather derivatives}

Weather derivatives are financial intruments based on a weather index which can be rain, snow, frost or temperature index. But the most traded contracts are the temperature-based contracts. The first reason of the success of the temperature-based derivatives is that they correspond to the need of the power companies which are among the principal actors of the market. The second reason is that temperature is a more manageable parameter than the rain or the snow which is subject to discontinuities (Dischel (1999)). These contracts are structured as options, futures and forwards based on an index which is usually an accumulation of the heating degree-days (HDDs) during the winter period (from November to March) or the cooling degree-days (CDDs) during the summer period (from May to September ${ }^{1}$ ). The HDD for day $\mathrm{j}$ is calculated by

$$
\mathrm{HDD}_{\mathrm{j}}=\max \left(65^{\circ} \mathrm{F}-\mathrm{T}_{\mathrm{j}}, 0\right)
$$

and the CDD for day $\mathrm{j}$ is given by

$$
\mathrm{CDD}_{\mathrm{j}}=\max \left(\mathrm{T}_{\mathrm{j}}-65^{\circ} \mathrm{F}, 0\right)
$$

where $65^{\circ}$ Fahrenheit is the reference temperature, $T_{j}$ denotes the average temperature for day $\mathrm{j}$ and it is defined as

$$
\mathrm{T}_{\mathrm{j}}=\frac{\mathrm{T}_{\mathrm{j}}^{\max }+\mathrm{T}_{\mathrm{j}}^{\min }}{2}
$$

The names HDD and CDD come from the US energy sector. It is considered that above the reference level of $65^{\circ} \mathrm{F}\left(\approx 18^{\circ}\right.$ Celcius $)$ people start turning their air conditioners on for cooling and below $65^{\circ} \mathrm{F}$ people start heating their homes.

The HDD and CDD indexes are respectively the number of HDDs and CDDs over a period of $\mathrm{n}$ days :

$$
\mathrm{I}_{\mathrm{n}}^{\mathrm{H}}=\sum_{\mathrm{j}=1}^{\mathrm{n}} \mathrm{HDD}_{\mathrm{j}} \quad \text { and } \quad \mathrm{I}_{\mathrm{n}}^{\mathrm{C}}=\sum_{\mathrm{j}=1}^{\mathrm{n}} \mathrm{CDD}_{\mathrm{j}}
$$

Contracts can also be based on the cumulative average temperature which is the case for contracts traded on Euronext.liffe (Marteau et al. (2004))

\subsection{Weather options}

There are two types of weather options : calls and puts ${ }^{2}$. A call option allows a company to protect itself against the high index levels $\left(\mathrm{I}_{\mathrm{n}}^{\mathrm{H}}\right.$ or $\left.\mathrm{I}_{\mathrm{n}}^{\mathrm{C}}\right)$ and a put option allows a company to

\footnotetext{
1 April and October are referred to as the 'shoulder months'. They are usually excluded from contracts because fluctuations during these months are greater than during the other months of the year.

2 Combination strategies can be developed with calls and puts like collars, strangles, spreads and straddles.
} 
hedge against the low index levels. A call option gives to the buyer the following amount (the payoff ${ }^{3}$ ) at the expiration date $t_{n}$ of the contract ${ }^{4}$ :

$$
\mathrm{C}\left(\mathrm{t}_{\mathrm{n}}\right)=\delta \cdot \max \left(\mathrm{I}_{\mathrm{n}}^{\mathrm{H}}-\mathrm{K}, 0\right) \text { during the winter period }
$$

and

$$
\mathrm{C}\left(\mathrm{t}_{\mathrm{n}}\right)=\delta \cdot \max \left(\mathrm{I}_{\mathrm{n}}^{\mathrm{C}}-\mathrm{K}, 0\right) \text { during the summer period }
$$

where $\delta$ is the tick size which represents the value of one degree-day and $\mathrm{K}$ is the strike level.

The company which wants to protect itself against a loss of turnover due to an overly cold winter will buy a HDD call option. At the beginning of the contract, it specifies with the seller the strike level K, the tick size $\delta$ and the contract period. If at the end of the contract period the actual index $\mathrm{I}_{\mathrm{n}}^{\mathrm{H}}$ is above the strike level, the company will receive the amount $\delta\left(\mathrm{I}_{\mathrm{n}}^{\mathrm{H}}-\mathrm{K}\right)$. Otherwise, it will receive nothing.

A put option provides to the buyer the following amount :

and

$$
\mathrm{P}\left(\mathrm{t}_{\mathrm{n}}\right)=\delta \cdot \max \left(\mathrm{K}-\mathrm{I}_{\mathrm{n}}^{\mathrm{H}}, 0\right) \text { during the winter period }
$$

$$
\mathrm{P}\left(\mathrm{t}_{\mathrm{n}}\right)=\delta \cdot \max \left(\mathrm{K}-\mathrm{I}_{\mathrm{n}}^{\mathrm{C}}, 0\right) \text { during the summer period. }
$$

The company which wants to protect itself against a loss of turnover due to an overly warm winter will buy a HDD put option. If at the end of the contract period, the actual index $\mathrm{I}_{\mathrm{n}}^{\mathrm{H}}$ is below the strike level, the company will receive the amount $\delta\left(K-I_{n}^{H}\right)$. Otherwise, it will receive nothing.

An example of the weather hedge can be found in Müller and Grandi (2000).

The form of the payoffs is due to the fact that these contracts give the right but not the obligation to buy (in the case of the call options) or to sell (in the case of the put options) the index ${ }^{5} \mathrm{I}_{\mathrm{n}}^{\mathrm{H}}$ (or $\mathrm{I}_{\mathrm{n}}^{\mathrm{C}}$ ) at the expiration date of the contract. This privilege requires to pay a premium to enter one of these contracts.

Their price corresponds to the premium to be paid at the beginning of the period contract. It is given at time $\mathrm{t}$ by

$$
\mathrm{C}\left(\mathrm{t}, \mathrm{t}_{\mathrm{n}}\right)=\mathrm{e}^{-\mathrm{r}\left(\mathrm{t}_{\mathrm{n}}^{-\mathrm{t}}\right)} \delta \cdot \mathrm{E}^{\mathrm{Q}}\left[\max \left(\mathrm{I}_{\mathrm{n}}^{\mathrm{H}}-\mathrm{K}, 0\right) \mid F_{\mathrm{t}}\right] \quad \text { for the HDD call option }
$$

and

$$
\mathrm{P}\left(\mathrm{t}, \mathrm{t}_{\mathrm{n}}\right)=\mathrm{e}^{-\mathrm{r}\left(\mathrm{t}_{\mathrm{n}}^{-\mathrm{t}}\right)} \delta \cdot \mathrm{E}^{\mathrm{Q}}\left[\max \left(\mathrm{K}-\mathrm{I}_{\mathrm{n}}^{\mathrm{H}}, 0\right) \mid F_{\mathrm{t}}\right] \quad \text { for the HDD put option }
$$

where $\mathrm{r}$ refers to the riskless interest rate, $F_{\mathrm{t}}$ corresponds to the information available at time $\mathrm{t}$ and $E^{\mathrm{Q}}$ represents the expectation operator under the probability $\mathrm{Q}$ which is often called the risk-neutral probability or the equivalent martingale measure. We will discuss this notion later.

\footnotetext{
3 It is also called payout from the seller's point of view.

4 Weather options are European contracts.

5 No HDDs or CDDs are of course delivered at the end of the contract. There are no physical transactions. Only money is tranferred between the seller and the buyer of the weather option.
} 
We replace $\mathrm{I}_{\mathrm{n}}^{\mathrm{H}}$ by $\mathrm{I}_{\mathrm{n}}^{\mathrm{C}}$ in Eq.(9) and Eq.(10) for the CDD call and put option.

In fact, weather options are call and put spreads instead of calls and puts in traditional sense because they have a cap on the maximum payoff. Their value is expressed as

$$
\mathrm{C}\left(\mathrm{t}_{\mathrm{n}}\right)=\delta \cdot \max \left[\operatorname{Min}\left(\mathrm{I}_{\mathrm{n}}^{\mathrm{H}}-\mathrm{K}, \mathrm{I}_{\mathrm{n}}^{\mathrm{H}, \max }-\mathrm{K}\right), 0\right] \text { for a HDD call spread }
$$

where $\mathrm{I}_{\mathrm{n}}^{\mathrm{H}, \max }>\mathrm{I}_{\mathrm{n}}^{\mathrm{H}}$, and

$$
\mathrm{P}\left(\mathrm{t}_{\mathrm{n}}\right)=\delta \cdot \max \left[\operatorname{Min}\left(\mathrm{K}-\mathrm{I}_{\mathrm{n}}^{\mathrm{H}}, \mathrm{K}-\mathrm{I}_{\mathrm{n}}^{\mathrm{H}, \min }\right), 0\right] \text { for a HDD put spread }
$$

where $\mathrm{I}_{\mathrm{n}}^{\mathrm{H}, \min }<\mathrm{I}_{\mathrm{n}}^{\mathrm{H}}$.

We replace $\mathrm{I}_{\mathrm{n}}^{\mathrm{H}}$ by $\mathrm{I}_{\mathrm{n}}^{\mathrm{C}}$ in the case of the CDD call and put spreads.

For the sake of simplicity, we will not consider the payoff of the spreads and will only focus on the payoff of the calls and puts.

\subsection{Weather futures and weather forwards}

Companies have also the possibility to protect themselves by using weather futures which are traded on the standardized markets like the Chicago Mercantile Exchange (CME) or by using weather forwards which are traded OTC (Over-the-Counter). Unlike futures, forwards are mostly capped. The CME contracts are monthly and seasonal ones based on HDDs and CDDs for 15 locations in the US, 5 in Europe and 2 in Japan ${ }^{6}$. By writing a weather futures, a company can sell or buy the index $\mathrm{I}_{\mathrm{n}}^{\mathrm{H}}$ ( or $\mathrm{I}_{\mathrm{n}}^{\mathrm{C}}$ ) according to their hedging strategy. The company which wants to protect itself against a loss of turnover due to an overly cold winter will buy the index $\mathrm{I}_{\mathrm{n}}^{\mathrm{H}}$. It predetermines the level $\mathrm{K}$ of the index $\mathrm{I}_{\mathrm{n}}^{\mathrm{H}}$ (the strike level) at which it will buy it at the end of the contract period. On the contrary to the weather options, the company pays no premium to enter into the weather futures or the weather forwards but it has the obligation to buy the index $\mathrm{I}_{\mathrm{n}}^{\mathrm{H}}$ at the predetermined level $\mathrm{K}$ at the end of the contract. If the actual level of the index $\mathrm{I}_{\mathrm{n}}^{\mathrm{H}}$ is above $\mathrm{K}$ at maturity, the company will win the amount $\delta\left(\mathrm{I}_{\mathrm{n}}^{\mathrm{H}}-\mathrm{K}\right)$ since it will buy the index at the level $\mathrm{K}<\mathrm{I}_{\mathrm{n}}^{\mathrm{H}}$ and will sell it at the level $\mathrm{I}_{\mathrm{n}}^{\mathrm{H}}$. But it will loose the amount $\delta\left(\mathrm{K}-\mathrm{I}_{\mathrm{n}}^{\mathrm{H}}\right)$ if $\mathrm{I}_{\mathrm{n}}^{\mathrm{H}}$ is below $\mathrm{K}$ because it has to buy the index $\mathrm{I}_{\mathrm{n}}^{\mathrm{H}}$ at level $\mathrm{K}$ and will sell it at level $\mathrm{I}_{\mathrm{n}}^{\mathrm{H}}$. In fact, weather futures are cash-settled contracts, which means that there is a daily markingto-market based upon the index, with the gain or loss applied to the customer's account.

The quoted price of the weather futures corresponds to the strike level $\mathrm{K}$. At time $\mathrm{t}$, it is defined as

and

$$
\mathrm{F}\left(\mathrm{t}, \mathrm{t}_{\mathrm{n}}\right)=\delta \cdot \mathrm{E}^{\mathrm{Q}}\left[\mathrm{I}_{\mathrm{n}}^{\mathrm{H}} \mid F_{\mathrm{t}}\right] \text { for a HDD weather futures }
$$

$$
\mathrm{F}\left(\mathrm{t}, \mathrm{t}_{\mathrm{n}}\right)=\delta . \mathrm{E}^{\mathrm{Q}}\left[\mathrm{I}_{\mathrm{n}}^{\mathrm{C}} \mid F_{\mathrm{t}}\right] \text { for a CDD weather futures. }
$$

\footnotetext{
6 For European and Japanese cities, the cumulative average temperature (CAT) is used instead of the cumulative HDD and CDD.
} 
Since the underlying of the weather futures is not a traded asset, we cannot apply the cost of carry formula to price them. Following Benth and Saltytė-Benth (2005), we use the risk neutral pricing formula of Eq.(9) or Eq.(10) to derive Eq.(13) and Eq.(14) by assuming that $\mathrm{C}\left(\mathrm{t}, \mathrm{t}_{\mathrm{n}}\right)$ is zero since no premium is required to write the weather futures. This method was already used to price the electricity futures (Geman and Vasicek (2001)) and the catastrophe futures (Cummins and Geman (1994)).

For computing the prices, an assumption about the process of the daily average temperature must be made. The modelling of the average temperature is preferred to that of the index in order to take advantage of the whole historical data of the temperature when estimating the process. Indeed some information is lost when constructing the HDD or the CDD index since we only consider the daily average temperature below $65^{\circ} \mathrm{F}$ in the case of the HDD index and above $65^{\circ} \mathrm{F}$ for the CDD index. In the other cases, we have values equal to zero for the indexes. In the following, we examine the New York daily average temperature time series to find the proper process for it.

\section{A mean-reverting jump-EGARCH diffusion process for the temperature}

\subsection{Analysis of the weather data}

Alaton et al. (2002) and Brody et al. (2002) suppose that the daily average temperature follows a mean-reverting diffusion process driven by a standard Brownian motion since they show that the curve of distribution of the daily average temperature variations is similar to that of the normal distribution. But no test was provided to confirm this assumption. We show in Fig. 1 that this hypothesis is rejected with the Jarque-Bera statistic. We use the daily average temperature data of the New York LaGuardia airport for the period from January 1993 to July 2005 which represents 4595 observations. We call this time series TAVGNY. We implement the test with Eviews for the differencied TAVGNY series that we call DTAVGNY. We observe in Fig.1 that the probability that the Jarque-Bera statistic exceeds the value of 112.71 under the null hypothesis is close to zero. Therefore, we conclude that the DTAVGNY series is not normally distributed. Benth and Saltyte-Benth (2005) came to the same conclusion with the chi-square goodness-of-fit test applied to seven cities in Norway.
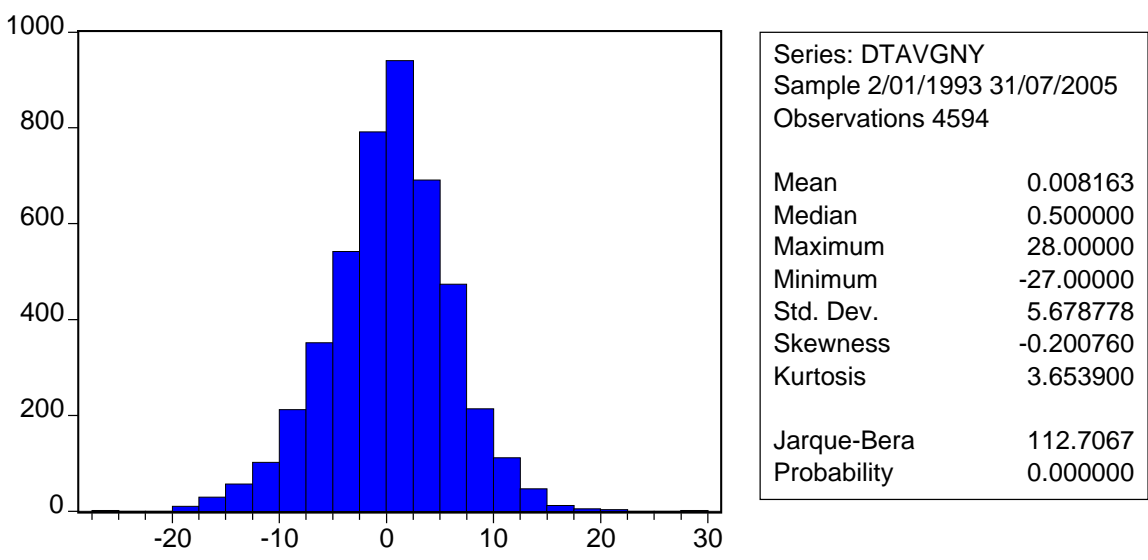

Fig. 1 Descriptive statistics for the DTAVGNY series 


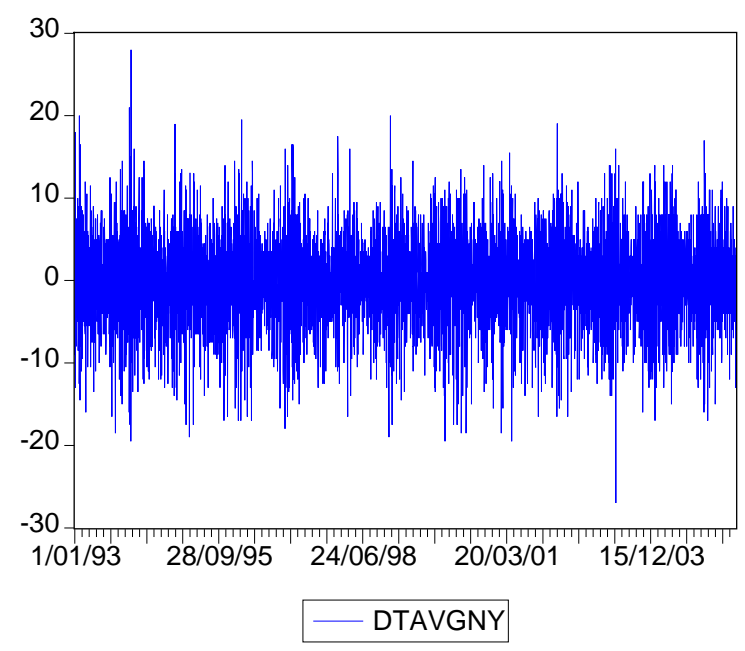

Fig. 2 Variations of the TAVGNY series

In sight of Fig.2, we notice that the TAVGNY series is quite volatile. We can consider to capture this time-varying volatility with an EGARCH (Exponential Generalized AutoRegressive Conditional Heteroskedasticity) process. An EGARCH(p,q) process is defined as

$$
\ln \sigma_{\mathrm{t}}^{2}=\alpha_{0}+\sum_{\mathrm{i}=1}^{\mathrm{q}} \alpha_{\mathrm{i}}\left(\Phi \mathrm{z}_{\mathrm{t}-\mathrm{i}}+\psi\left[\left|\mathrm{z}_{\mathrm{t}-\mathrm{i}}\right|-\mathrm{E}\left|\mathrm{z}_{\mathrm{t}-\mathrm{i}}\right|\right]\right)+\sum_{\mathrm{j}=1}^{\mathrm{p}} \beta_{\mathrm{j}} \ln \sigma_{\mathrm{t}-\mathrm{j}}^{2}
$$

where $\sigma_{\mathrm{t}}^{2}$ is the conditional variance, $\mathrm{z}_{\mathrm{t}-\mathrm{i}}=\frac{\varepsilon_{\mathrm{t}-\mathrm{i}}}{\sigma_{\mathrm{t}-\mathrm{i}}}$ represents the standardized innovation and $\varepsilon_{\mathrm{t}} \sim N\left(0, \sigma_{\mathrm{t}}^{2}\right)$ is the innovation. An $\mathrm{ARCH}(1)$ process was used by Richards, Manfredo and Sanders (2004) to model the volatility of the temperature in Fresno in California. It is expressed as

$$
\sigma_{\mathrm{t}}^{2}=\alpha_{0}+\alpha_{1} \varepsilon_{\mathrm{t}-1}^{2}, \quad \alpha_{0}>0 \text { and } \alpha_{1} \geq 0
$$

Because of the positiveness constraints of the coefficients which means that the conditional variance depends only on the magnitude and not on the sign of the innovations, we decide to choose an EGARCH $(1,1)$ process to take into account asymmetric effets of the innovations.

We also want to account for jumps in the temperatures as did Richards, Manfredo and Sanders (2004) because sudden rises and falls in the temperatures are observed.

Thus we suggest the following mean-reverting jump-EGARCH diffusion process for the daily average temperature :

$$
\mathrm{dT}_{t}=\left[\frac{d T_{t}^{m}}{d t}+a\left(T_{t}^{m}-T_{t}\right)\right] d t+\sigma_{t} d W_{t}+U d q_{t}
$$

or

$$
\mathrm{dT}_{t}=\left[\frac{\mathrm{dT}_{t}^{\mathrm{m}}}{\mathrm{dt}}+\mathrm{a}\left(\mathrm{T}_{\mathrm{t}}^{\mathrm{m}}-\mathrm{T}_{\mathrm{t}}\right)\right] \mathrm{dt}+\sigma_{\mathrm{t}} \mathrm{dW}_{\mathrm{t}}+\mathrm{U} \times\left\{\begin{array}{ll}
1 & \text { with probability } \gamma d t \\
0 & \text { with probability } 1-\gamma d t
\end{array} .\right.
$$


Using the integral form of the process, we get :

$$
\mathrm{T}_{\mathrm{t}}=\mathrm{T}_{0}+\int_{0}^{\mathrm{t}}\left[\frac{\mathrm{dT}_{\mathrm{s}}^{\mathrm{m}}}{\mathrm{ds}}+\mathrm{a}\left(\mathrm{T}_{\mathrm{s}}^{\mathrm{m}}-\mathrm{T}_{\mathrm{s}}\right)\right] \mathrm{ds}+\int_{0}^{\mathrm{t}} \sigma_{\mathrm{s}} \mathrm{dW}_{\mathrm{s}}+\sum_{\mathrm{k}=1}^{\mathrm{N}(\mathrm{t})} \mathrm{U}_{\mathrm{k}} \mathrm{dq}_{\mathrm{k}},
$$

where $\varepsilon_{\mathrm{t}}=\int_{0}^{\mathrm{t}} \sigma_{\mathrm{s}} \mathrm{dW}$ and with ${ }^{7}$

$$
\ln \sigma_{\mathrm{t}}^{2}=\omega_{0}+\omega_{1}\left|\frac{\varepsilon_{\mathrm{t}-1}}{\sigma_{\mathrm{t}-1}}\right|+\omega_{2} \frac{\varepsilon_{\mathrm{t}-1}}{\sigma_{\mathrm{t}-1}}+\beta_{1} \ln \sigma_{\mathrm{t}-1}^{2}
$$

where $\mathrm{a}$ is the speed of the mean-reversion, $\sigma_{\mathrm{t}}$ is the volatility of the temperature, $\mathrm{dW}_{\mathrm{t}}$ represents the standard Wiener process then we have $\mathrm{dW}_{\mathrm{t}}=\widetilde{\varepsilon}_{\mathrm{t}} \sqrt{\mathrm{dt}}$ with $\widetilde{\varepsilon}_{\mathrm{t}} \sim N(0,1), \mathrm{N}(\mathrm{t})$ is a Poisson process accounting for the number of jumps up to $t, U_{k}$ denotes the jump size of the k-th jump, $\mathrm{U}_{\mathrm{k}} \sim N\left(\mu_{\mathrm{U}}, \sigma_{\mathrm{U}}^{2}\right)$, the probability of occurence of one jump during a time interval of length $\mathrm{dt}$ is $\gamma \mathrm{dt}$ and the probability of no jump during this time interval is $1-\gamma \mathrm{dt}, \gamma$ refers to the intensity of the Poisson process, $\mathrm{U}_{\mathrm{k}}, \mathrm{dN}_{\mathrm{t}}$ and $\mathrm{dW}_{\mathrm{t}}$ are assumed to be independent and $\mathrm{T}_{\mathrm{t}}^{\mathrm{m}}$ reflects the mean temperature defined by

$$
\mathrm{T}_{\mathrm{t}}^{\mathrm{m}}=\alpha+\beta \mathrm{t}+\zeta \sin (\omega \mathrm{t}+\varphi), \quad \omega=\frac{2 \pi}{365},
$$

where $\alpha, \beta, \zeta, \varphi$ are constants ,

$$
\frac{\mathrm{dT}_{\mathrm{t}}^{\mathrm{m}}}{\mathrm{dt}}=\beta+\omega \zeta \cos (\omega \mathrm{t}+\varphi)
$$

this term is required in Eq.(17) to allow the temperature to revert to the mean temperature in the long run (see Dornier and Queruel (2000)).

\subsection{Estimation of the parameters of the mean-reverting jump-EGARCH process}

To estimate our process, we employ the Ball and Torous (1985)'s method. It consists in maximizing the logarithm of the likelihood function. Let the variate $\mathrm{S}$ obey a jump diffusion process which is expressed as

$$
\frac{\mathrm{dS}}{\mathrm{S}}=\alpha \mathrm{dt}+\sigma \mathrm{dW}+(\mathrm{Y}-1) \mathrm{dq}
$$

where $\mathrm{W}$ and $\mathrm{q}$ are respectively the Wiener and the Poisson process with parameter $\gamma \mathrm{t}$. The jump size $\mathrm{Y}$ is distributed lognormal with $\ln \mathrm{Y} \sim N\left(\mu, \delta^{2}\right)$.

\footnotetext{
$7 \operatorname{An} \operatorname{EGARCH}(1,1)$ process is written as $\ln \sigma_{\mathrm{t}}^{2}=\alpha_{0}+\omega_{1} \mathrm{z}_{\mathrm{t}-1}+\omega_{2}\left|\mathrm{z}_{\mathrm{t}-1}\right|-\omega_{2} \mathrm{E}\left|\mathrm{z}_{\mathrm{t}-1}\right|+\beta_{1} \ln \sigma_{\mathrm{t}-1}^{2}$ with $\mathrm{E}\left|\mathrm{z}_{\mathrm{t}-1}\right| \approx \sqrt{\frac{2}{\pi}}$ . Therefore, the estimation is carried out with the following equation : $\ln \sigma_{\mathrm{t}}^{2}=\omega_{0}+\omega_{1} \mathrm{z}_{\mathrm{t}-1}+\omega_{2}\left|\mathrm{z}_{\mathrm{t}-1}\right|+\beta_{1} \ln \sigma_{\mathrm{t}-1}^{2}$ where $\omega_{0}=\left(\alpha_{0}-\omega_{2} \sqrt{\frac{2}{\pi}}\right)$ is a constant.
} 
Let $\frac{\mathrm{dS}}{\mathrm{S}} \approx \ln \mathrm{S}_{\mathrm{t}+1}-\ln \mathrm{S}_{\mathrm{t}} \equiv \mathrm{Z}_{\mathrm{t}+1}$, the variate $\mathrm{Z}=\left\{\mathrm{z}_{1}, \mathrm{z}_{2}, \ldots, \mathrm{z}_{\mathrm{m}}\right\}$ has a density which is a mixture of Poisson and Gaussian densities ${ }^{8}$ :

$$
f(z)=\sum_{n=0}^{\infty} \frac{e^{-\gamma \Delta t}(\gamma \Delta t)^{n}}{n !}\left(2 \pi\left(\sigma^{2} \Delta t+n \delta^{2}\right)\right)^{-1 / 2} \exp \left[\frac{-(z-(\alpha \Delta t+n \mu))^{2}}{2\left(\sigma^{2} \Delta t+n \delta^{2}\right)}\right]
$$

where $\Delta \mathrm{t}=1$ and $\mathrm{n}$ corresponds to the number of events (i.e jumps) that occur.

The logarithm of the likelihood function of $\mathrm{Z}$ is written as

$$
\ln \mathrm{L}(\mathrm{Z} ; \theta)=\sum_{\mathrm{i}=1}^{\mathrm{m}} \ln \mathrm{f}\left(\mathrm{z}_{\mathrm{i}} ; \theta\right)
$$

where $\theta$ is a vector of parameters to estimate. This function has to be maximized to obtain the estimations.

Following Das (1998), we discretize the process (17) of the average temperature for the estimation. It is written as

where

$$
\Delta \mathrm{T}_{\mathrm{t}}=\Delta \mathrm{T}_{\mathrm{t}}^{\mathrm{m}}+\mathrm{a}\left(\mathrm{T}_{\mathrm{t}-1}^{\mathrm{m}}-\mathrm{T}_{\mathrm{t}-1}\right) \Delta \mathrm{t}+\sigma_{\mathrm{t}-1} \widetilde{\varepsilon} \sqrt{\Delta \mathrm{t}}+\mathrm{U} \Delta \mathrm{q}_{\mathrm{t}}
$$

$$
\ln \sigma_{\mathrm{t}-1}^{2}=\omega_{0}+\omega_{1}\left|\frac{\Delta \mathrm{T}_{\mathrm{t}-2}-\mathrm{E}\left(\Delta \mathrm{T}_{\mathrm{t}-2}\right)}{\sigma_{\mathrm{t}-2}}\right|+\omega_{2}\left(\frac{\Delta \mathrm{T}_{\mathrm{t}-2}-\mathrm{E}\left(\Delta \mathrm{T}_{\mathrm{t}-2}\right)}{\sigma_{\mathrm{t}-2}}\right)+\beta_{1} \ln \sigma_{\mathrm{t}-2}^{2},
$$

$\widetilde{\varepsilon}_{\mathrm{t}} \sim N(0,1)$ and $\mathrm{U} \sim>N\left(\mu_{\mathrm{U}}, \sigma_{\mathrm{U}}^{2}\right)$, which yields the following density function

$$
\mathrm{f}\left(\Delta \mathrm{T}_{\mathrm{t}}\right)=\sum_{\mathrm{n}=0}^{\infty} \frac{\mathrm{e}^{-\gamma \Delta \mathrm{t}}(\gamma \Delta \mathrm{t})^{\mathrm{n}}}{\mathrm{n} !}\left(2 \pi\left(\sigma_{\mathrm{t}-1}^{2} \Delta \mathrm{t}+\mathrm{n} \sigma_{\mathrm{U}}^{2}\right)\right)^{-1 / 2} \exp \left[\frac{-\left(\Delta \mathrm{T}_{\mathrm{t}}-\left(\Delta \mathrm{T}_{\mathrm{t}}^{\mathrm{m}}+\mathrm{a}\left(\mathrm{T}_{\mathrm{t}-1}^{\mathrm{m}}-\mathrm{T}_{\mathrm{t}-1}\right) \Delta \mathrm{t}+\mathrm{n} \mu_{\mathrm{U}}\right)\right)^{2}}{2\left(\sigma_{\mathrm{t}-1}^{2} \Delta \mathrm{t}+\mathrm{n} \sigma_{\mathrm{U}}^{2}\right)}\right]
$$

(28).

We need to truncate at $\mathrm{N}$ the infinite sum. To determine this number, Ball and Torous (1985) use a bound on the truncation error which allows to find $\mathrm{N}$ in such a way that some computer accuracy is satisfied. We propose here another method consisting in choosing $\mathrm{N}$ in such a way that the residuals of the estimated model are minimized. For this purpose, we use the statistic S

$$
\mathrm{s}=\sqrt{\frac{\mathrm{SSR}}{\mathrm{m}-\mathrm{k}}}
$$

where SSR is the sum of the squared residuals, $\mathrm{k}$ is the number of dependent variables and $\mathrm{m}$ is the number of observations. The selected number $\mathrm{N}$ will correspond to the smallest $\mathrm{s}$.

\footnotetext{
8 The Poisson-Gaussian density can be approximated by the Bernouilli mixture of Gaussian densities for small values of $(\gamma \Delta \mathrm{t})$ (see Ball and Torous (1985)).
} 
Residuals are expressed as

$$
\mathrm{R}_{\mathrm{t}}=\mathrm{D}_{\mathrm{t}}-\left(\hat{\sigma}_{\mathrm{t}-1} \widetilde{\varepsilon}_{\mathrm{t}} \sqrt{\Delta \mathrm{t}}+\hat{\gamma} \hat{\mu}_{\mathrm{U}} \Delta \mathrm{t}\right)
$$

where

$$
\begin{gathered}
\mathrm{D}_{\mathrm{t}}=\Delta \mathrm{T}_{\mathrm{t}}-\Delta \hat{\mathrm{T}}_{\mathrm{t}}^{\mathrm{m}}-\hat{\mathrm{a}}\left(\hat{\mathrm{T}}_{\mathrm{t}-1}^{\mathrm{m}}-\mathrm{T}_{\mathrm{t}-1}\right) \Delta \mathrm{t}, \\
\hat{\mathrm{T}}_{\mathrm{t}}^{\mathrm{m}}=\hat{\alpha}+\hat{\beta} \mathrm{t}+\hat{\zeta} \sin \left(\frac{2 \pi}{365} \mathrm{t}+\hat{\varphi}\right), \\
\Delta \varepsilon_{\mathrm{t}}=\sigma_{\mathrm{t}-1} \widetilde{\varepsilon}_{\mathrm{t}} \sqrt{\Delta \mathrm{t}} \approx \Delta \mathrm{T}_{\mathrm{t}}-\mathrm{E}\left(\Delta \mathrm{T}_{\mathrm{t}}\right), \\
\sigma_{\mathrm{t}-1} \widetilde{\varepsilon}_{\mathrm{t}} \sqrt{\Delta \mathrm{t}} \approx \Delta \mathrm{T}_{\mathrm{t}}-\left(\Delta \mathrm{T}_{\mathrm{t}}^{\mathrm{m}}+\mathrm{a}\left(\mathrm{T}_{\mathrm{t}-1}^{\mathrm{m}}-\mathrm{T}_{\mathrm{t}-1}\right) \Delta \mathrm{t}+\gamma \mu_{\mathrm{U}} \Delta \mathrm{t}\right), \\
\sigma_{\mathrm{t}-1} \widetilde{\varepsilon}_{\mathrm{t}} \sqrt{\Delta \mathrm{t}}+\gamma \mu_{\mathrm{U}} \Delta \mathrm{t} \approx \Delta \mathrm{T}_{\mathrm{t}}-\Delta \mathrm{T}_{\mathrm{t}}^{\mathrm{m}}-\mathrm{a}\left(\mathrm{T}_{\mathrm{t}-1}^{\mathrm{m}}-\mathrm{T}_{\mathrm{t}-1}\right) \Delta \mathrm{t}, \\
\ln \sigma_{\mathrm{t}-1}^{2}=\omega_{0}+\omega_{1}\left|\frac{\Delta \varepsilon_{\mathrm{t}-2}}{\sigma_{\mathrm{t}-2}}\right|+\omega_{2}\left(\frac{\Delta \varepsilon_{\mathrm{t}-2}}{\sigma_{\mathrm{t}-2}}\right)+\beta_{1} \ln \sigma_{\mathrm{t}-2}^{2},
\end{gathered}
$$

where $\Delta t=1, \widetilde{\varepsilon}_{\mathrm{t}} \sim N(0,1), \hat{\sigma}_{\mathrm{t}-1}, \hat{\mathrm{a}}, \hat{\alpha}, \hat{\beta}, \hat{\zeta}, \hat{\varphi}, \hat{\gamma}$ and $\hat{\mu}_{\mathrm{U}}$ are estimated parameters. Results are reported in Table 1. To obtain these estimates with the maximum likelihood method, we need to specify the initial values for the optimization problem. Following Ball and Torous (1985), we choose these values as the maximum likelihood estimates of a Bernouilli process.

\begin{tabular}{|c|c|c|}
\hline $\mathrm{N}$ & $\mathrm{LL}$ & $\mathrm{S}$ \\
\hline 1 & $-13978,93000000$ & 7,3644 \\
2 & $-13979,03000000$ & 7,3562 \\
3 & $-13978,65000000$ & 7,3060 \\
4 & $-13978,58000000$ & 7,2714 \\
5 & $-13978,57450000$ & 7,2637 \\
6 & $-13978,57417900$ & 7,2585 \\
7 & $-13978,57416850$ & 7,2608 \\
8 & $-13978,57416801$ & 7,2692 \\
9 & $-13978,57416803$ & 7,2665 \\
10 & $-13978,57416806$ & 7,2665 \\
\hline
\end{tabular}

Table 1 Estimated log likelihood function and s statistic ${ }^{9}$ for various $\mathrm{N}$

Even if $\mathrm{N}=8$ gives the biggest log likelihood value, we choose $\mathrm{N}=6$ which corresponds to the smallest $\mathrm{s}$. The estimated process is then given by

9 The same random value $\widetilde{\varepsilon}$ was applied for the computation of the residuals for the various $\mathrm{N}$. 


$$
\begin{gathered}
\mathrm{dT}_{\mathrm{t}}=\left[\frac{\mathrm{dT}_{\mathrm{t}}^{\mathrm{m}}}{\mathrm{dt}}+0.32\left(\mathrm{~T}_{\mathrm{t}}^{\mathrm{m}}-\mathrm{T}_{\mathrm{t}}\right)\right] \mathrm{dt}+\sigma_{\mathrm{t}} \mathrm{dW}_{\mathrm{t}}+\mathrm{Udq}_{\mathrm{t}}, \\
\hat{\mathrm{T}}_{\mathrm{t}}^{\mathrm{m}}=55.96-4.20 \times 10^{-5} \mathrm{t}+22.23 \sin \left(\frac{2 \pi}{365} \mathrm{t}-2\right), \\
\ln \hat{\sigma}_{\mathrm{t}}^{2}=-0.025+0.103\left|\frac{\Delta \hat{\varepsilon}_{\mathrm{t}-1}}{\hat{\sigma}_{\mathrm{t}-1}}\right|+0.015\left(\frac{\Delta \hat{\varepsilon}_{\mathrm{t}-1}}{\hat{\sigma}_{\mathrm{t}-1}}\right)+0.980 \ln \hat{\sigma}_{\mathrm{t}-1}^{2}, \\
\mathrm{U} \sim N(-0.42,13.91) \text { and } \hat{\gamma}=0.20 .
\end{gathered}
$$

\section{Weather derivatives and implied risk-neutral distribution}

The idea here is to extract the risk-neutral probability Q relative to the weather option we want to price from the weather futures which is based on the same underlying as the option and for which market prices are available.

Extracting the risk-neutral probability is a common task in the complete market setting when the option is too complex to derive an explicit pricing formula. For instance, Asian options based on an arithmetic average of the underlying prices have no closed-form expression for the value. The risk-neutral distribution is then derived from their observed values to price them. Financial contracts are priced by using the risk-neutral density of the underlying and not the historical one. For instance, the call option price at time $t$ is given by the following formula :

$$
\mathrm{C}\left(\mathrm{t}, \mathrm{t}_{\mathrm{n}}\right)=\mathrm{e}^{-\mathrm{r}\left(\mathrm{t}_{\mathrm{n}}-\mathrm{t}\right)} \mathrm{E}^{\mathrm{Q}}\left[\max \left(\mathrm{S}_{\mathrm{t}_{\mathrm{n}}}-\mathrm{K}, 0\right) \mid F_{\mathrm{t}}\right]=\mathrm{e}^{-\mathrm{r}\left(\mathrm{t}_{\mathrm{n}}-\mathrm{t}\right)} \int_{0}^{\infty} \max \left(\mathrm{S}_{\mathrm{t}_{\mathrm{n}}}-\mathrm{K}, 0\right) \mathrm{q}_{\mathrm{t}, \mathrm{t}_{\mathrm{n}}}\left(\mathrm{S}_{\mathrm{t}_{\mathrm{n}}}\right) \mathrm{dS}_{\mathrm{t}_{\mathrm{n}}}
$$

where $\mathrm{S}$ is the underlying asset price and $\mathrm{q}_{\mathrm{t}, \mathrm{t}_{\mathrm{n}}}$ is the risk-neutral density of the variate $\mathrm{S}_{\mathrm{t}_{\mathrm{n}}}$.

An equivalent martingale measure is a measure under which the discounted underlying asset $\mathrm{e}^{-\mathrm{rt}} \mathrm{S}$ process is a martingale.

This measure $\mathrm{Q}$ is said to be equivalent to the historical one (often called $\mathrm{P}$ ) if for any event $A, P(A)=0$ if and only if $Q(A)=0$.

To derive the density q from the observed option prices, an optimization problem must be solved and it is expressed as follows :

$$
\operatorname{Min}_{q_{t}} \sum_{t}\left(C\left(t, t_{n}\right)-C^{\text {observed }}\left(t, t_{n}\right)\right)^{2}
$$

where $\mathrm{C}\left(\mathrm{t}, \mathrm{t}_{\mathrm{n}}\right)$ is the theoretical price at time $\mathrm{t}$ for the expiration date $\mathrm{t}_{\mathrm{n}}$.

When the market is complete, that is when every contingent claim can be perfectly replicated by a self-financing portfolio stragegy based on the underlying asset (the contingent claim is said to be attainable), the principle of absence of arbitrage leads to a unique price for the 
contingent claim. This price is said to be preference free. The equivalent martingale measure Q is unique in this case (see Harrison and Pliska (1981)).

When the market is incomplete, the contingent claim is not attainable (because of frictions in the market), the principle of absence of arbitrage is no more enough to derive a unique price for the contingent claim. There exists an arbitrage-free interval (see Karatzas and Kou (1996)) for the prices which depend on the risk preference of the agents. Equivalent martingale measure is no more unique. To select one to price the contingent claim, some authors propose to find trading strategies which minimize the variance of the hedging errors (see Föllmer and Sondermann (1986), Föllmer and Schweizer (1991), Duffie and Richardson (1991), Schweizer (1992), Schweizer (1996)). Theses trading strategies lead to the minimal martingale measure (when the self-financing portfolio is replaced by the mean self-financing one) and to the variance-optimal martingale measure (when we keep the self-financing portfolio but we relax the perfect replication). One cannot have simultaneously the perfect replication and the self-financing portfolio when the market is incomplete. Other authors suggest that agents try to maximize their expected utility when they trade in an incomplete market. This leads to the minimal entropy martingale measure when the utility function is exponential (see Rouge and El Karoui (2000) and Fritelli (2000)).

The equivalent martingale probability inferred from the observed prices may correspond to one of the above martingale measures when the market is incomplete. But here we do not need to identify it to price the derivatives. We just have to insert it in Eq.(9) or Eq.(10) to obtain the weather option price.

But there are no available weather option prices to derive this equivalent martingale probability. We only have quoted weather futures prices. We see from Eq.(9) and Eq.(13) that weather options and weather futures have the same risk-neutral distribution providing that they are based upon the same underlying. So we will use the weather futures prices to extract the risk-neutral density in order to price the weather options.

\section{Extracting the risk-neutral distribution by using Monte-Carlo simulations}

Many techniques are available to extract the risk-neutral density. There are parametric and non parametric methods. Parametric methods require assumption about the form of the riskneutral distribution of the underlying. For instance, Bahra (1997) uses a mixture of two lognormal distributions. Jackwerth and Rubinstein (1996) suggest to find the smoothest riskneutral density by adding a regularizer to the optimization problem which penalizes for nonsmoothness. On the contrary to the parametric methods, non parametric approaches make no assumption about the form of the risk-neutral or state price density which can be extracted directly or not from the option prices. Breeden and Litzenberger (1978) and Aït-Sahalia and Lo (2000) estimate the state price density by differentiating the option price $\mathrm{C}(\mathrm{K}, \mathrm{T})$ twice with respect to the strike price $\mathrm{K}$ :

$$
q=e^{r(T-t)} \frac{\partial^{2} C(K, T)}{\partial K^{2}}
$$

where $\mathrm{T}$ is the maturity date and $\mathrm{r}$ is the riskless interest rate. Many of these methods are based on the knowledge of the explicit form of the option price which is most of the time given by the Black and Scholes formula. In our case, no analytical value can be found for the weather options and weather futures. To extract the risk-neutral distribution, we will adopt the Jackwerth and Rubinstein (1996)'s method which allows us not to calculate explicitly the 
price of the weather derivatives. We modify the method by incorporating Monte-Carlo simulations so as to take into account the jumps and the time-varying volatility of the underlying process.

\subsection{Optimization problem}

We want to simulate $\mathrm{N}$ paths for the average temperature and to construct $\mathrm{N}$ degree-day indexes. We will assign the risk-neutral probability q to each of these indexes. Then, we will have to estimate $\mathrm{N}$ probabilities. The optimization problem (42) becomes underdetermined because the number of prices in the market is too limited to allow us to find a unique solution for q. Futhermore, the problem is ill-posed, that is to say, the estimated solutions will not be stable. Small changes in the data input (i.e., in the futures quotes) can lead to large changes in the estimates. We must introduce a regularizer to stabilize the solutions. We follow Jackwerth and Rubinstein (1996) by imposing the minimization of the second derivative of $\mathrm{q}$ with respect to the underlying which is here the temperature $\mathrm{T}$, i.e.

$$
\sum_{\mathrm{k}=1}^{\mathrm{N}}\left(\mathrm{q}_{\mathrm{k}}^{\prime \prime}\right)^{2} \text { where } \mathrm{q}_{\mathrm{k}}^{\prime \prime} \approx \frac{\mathrm{q}_{\mathrm{k}-1}-2 \mathrm{q}_{\mathrm{k}}+\mathrm{q}_{\mathrm{k}+1}}{\Delta \mathrm{T}_{\mathrm{k}}^{2}} \approx \mathrm{q}_{\mathrm{k}-1}-2 \mathrm{q}_{\mathrm{k}}+\mathrm{q}_{\mathrm{k}+1} \text { with } \mathrm{q}_{0}=\mathrm{q}_{\mathrm{N}+1}=0 \text {. }
$$

This constraint will provide smoothed solutions. In addition, we require the solutions to be positive and the sum of the probabilities to be equal to one. Like Jackwerth and Rubinstein (1996), we transform this constrained optimization into an unconstrained one by using a penalty method where a penalty parameter has to be chosen. Our optimization problem is then written as

$$
\underset{\mathrm{q}_{\mathrm{k}}}{\operatorname{Min}} \sum_{\mathrm{i}=1}^{\mathrm{M}}\left(\mathrm{E}_{\mathrm{i}}^{\mathrm{Q}}\left[\mathrm{I}_{\mathrm{n}}^{\mathrm{C}}\right]-\mathrm{F}_{\mathrm{i}}\right)^{2}+\alpha\left(\sum_{\mathrm{k}=1}^{\mathrm{N}} \mathrm{q}_{\mathrm{k}}-1\right)^{2}+\alpha \sum_{\mathrm{k}=1}^{\mathrm{N}} \max \left(0,-\mathrm{q}_{\mathrm{k}}\right)^{2}+\alpha \sum_{\mathrm{k}=1}^{\mathrm{N}}\left(\mathrm{q}_{\mathrm{k}}^{\prime \prime}\right)^{2}
$$

where $\alpha>0$ is the penalty parameter, $E_{i}^{Q}\left[I_{n}^{C}\right]$ refers to the theoretical price of the weather futures as discussed in part $2.2, \mathrm{~F}_{\mathrm{i}}$ denotes the quoted weather futures price for day $\mathrm{i}$ and $\mathrm{M}$ corresponds to the number of available quotes.

For $\alpha \rightarrow 0(\alpha \neq 0)$, the estimated prices will be close to the observations but the solutions of the optimization problem will exhibit picks while for $\alpha \rightarrow+\infty$, the estimates will not reproduce well the observations but the solutions will form a smoothed curve. In our case, we will only favour big values for $\alpha$.

Other regularizers are also possible like the relative entropy or Kullback Leibler distance of the measure Q with respect to the historical measure P (see Stutzer (1996)). It is particularly appropriate for positive solutions but it requires as Jackwerth and Rubinstein (1996) point out a specific optimization routine to deal with.

To extract the risk-neutral probabilities, we simulate $\mathrm{N}$ paths for the average temperature and we calculate $\mathrm{N}$ indexes $\mathrm{I}_{\mathrm{n}}^{\mathrm{C}}$ which corresponds to the accumulation of the CDDs : 


$$
I_{n, k}^{C}=\sum_{j=1}^{n} C D_{j, k}=\sum_{j=1}^{n} \max \left(T_{j, k}-65,0\right) \quad \text { for } k=1, \ldots, N \text {. }
$$

We repeat this operation $\mathrm{M}$ times to obtain $\mathrm{N} \times \mathrm{M}$ indexes. We assume here that the number of available quotes is equal to the number of days of the period contract $(M=n)$.

Now our optimization problem can be rewritten as

$\underset{\mathrm{q}_{\mathrm{k}}}{\operatorname{Min}} \sum_{\mathrm{i}=1}^{\mathrm{M}}\left(\left(\sum_{\mathrm{k}=1}^{\mathrm{N}} \mathrm{I}_{\mathrm{n}, \mathrm{k}}^{\mathrm{C}} \mathrm{q}_{\mathrm{k}}\right)_{\mathrm{i}}-\mathrm{F}_{\mathrm{i}}\right)^{2}+\alpha\left(\sum_{\mathrm{k}=1}^{\mathrm{N}} \mathrm{q}_{\mathrm{k}}-1\right)^{2}+\alpha \sum_{\mathrm{k}=1}^{\mathrm{N}} \max \left(0,-\mathrm{q}_{\mathrm{k}}\right)^{2}+\alpha \sum_{\mathrm{k}=1}^{\mathrm{N}}\left(\mathrm{q}_{\mathrm{k}}^{\prime \prime}\right)^{2}$

We assume that temperatures before the date of observation of the futures price are known. Therefore, simulations of the temperatures will only be run for days after this date (including the date of observation of the price).

Simulations are conducted with Eq.(26). In order to simulate the occurrence of the jump, we create an independently and uniformly distributed number on [0,1]. If this number $<\gamma \Delta t$, a jump of size $U$ occurs during the time interval $\Delta \mathrm{t}$. If this number $\geq \gamma \Delta \mathrm{t}$, no jump occurs during the time interval.

We propose to use this optimization problem formulation to infer the risk-neutral density from the monthly New York weather futures prices with maturity date in August 2004. Next we will employ it to price the contract with expiration date in August 2005 for which we dispose of observations. Thus we will be able to consider the goodness of fit of the estimated prices and the ability of the temperature process and of the implied risk-neutral distribution to forecast prices since the temperature process as we mentioned before was estimated for the period of January 1993 through July 2005. The samples of prices for August 2004 and August 2005 contain only 22 prices from August $1^{\text {st }}$ through August $31^{\text {st }}$ since contracts are quoted only 5 day weeks. They are quoted in CDD index points and are plotted below in Fig. 3 and in Fig.4. In Fig.5 and Fig.6, we represent the daily average temperatures at LaGuardia Airport for the same period as the contracts. 


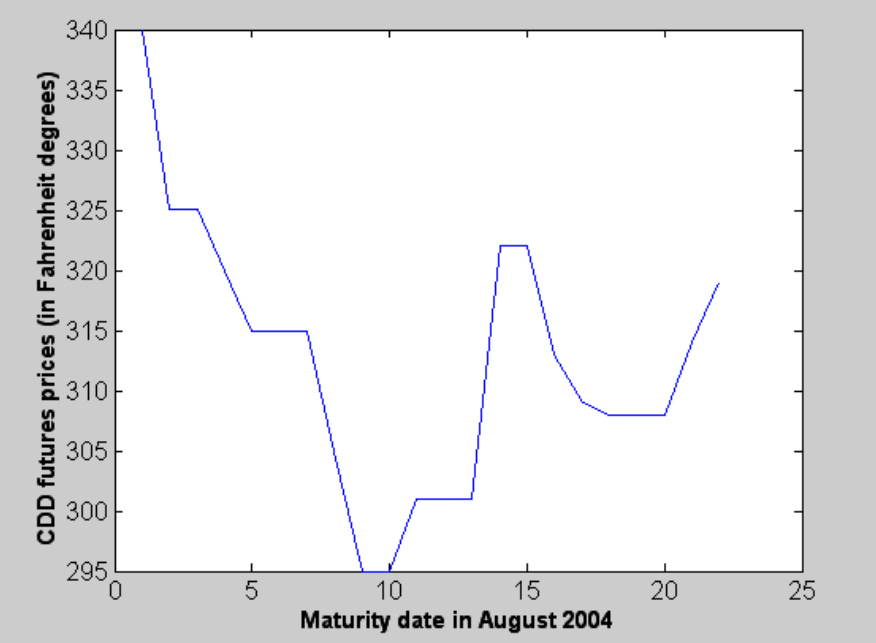

Fig.3 New York CDD futures quotations with expiration date in August 2004

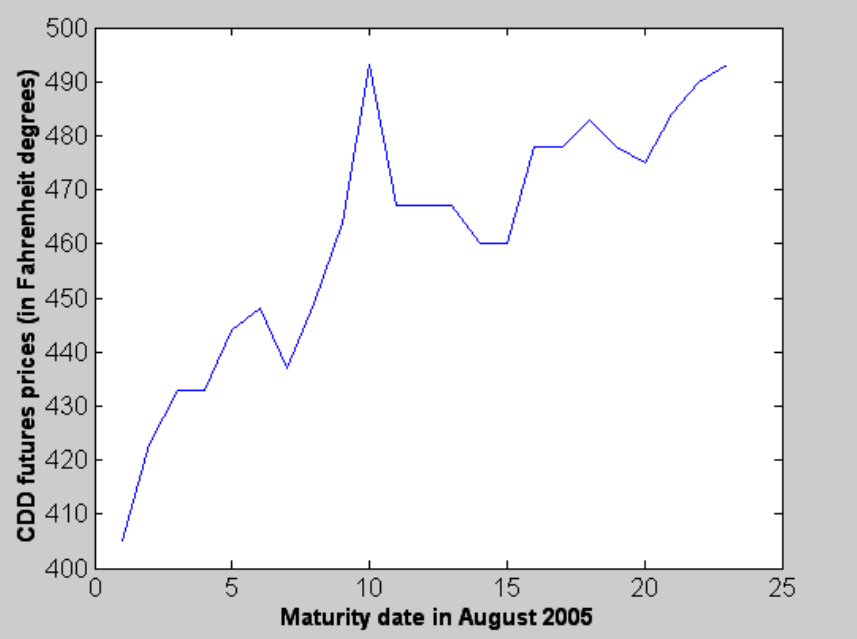

Fig.4 New York CDD futures quotations with expiration date in August 2005 


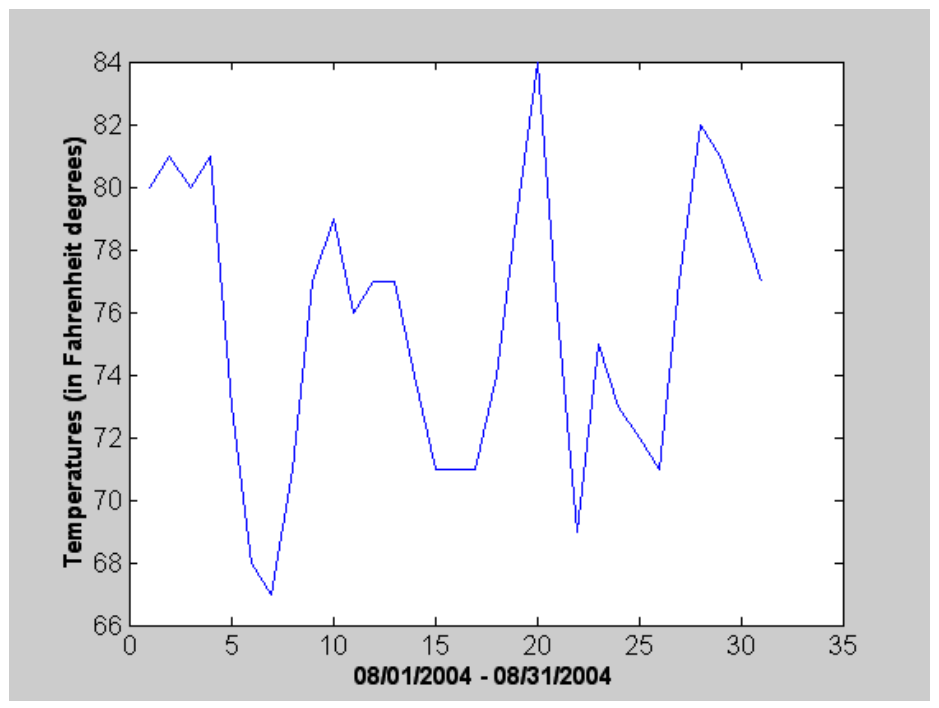

Fig.5 Daily average temperatures at LaGuardia Airport in August 2004

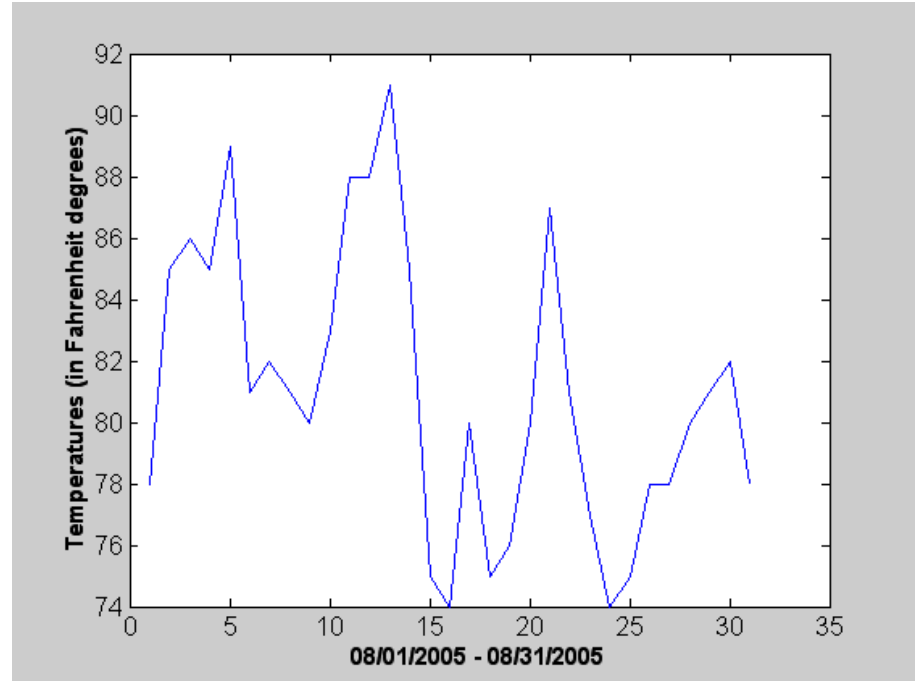

Fig.6 Daily average temperatures at LaGuardia Airport in August 2005

\subsection{Results}

We see in Fig. 8 that simulations for each day by using the observed temperatures as the initial values and the implied risk-neutral density shown in Fig. 7 induce very volatile prices while the quoted prices are smoothed. They do not evolve instantaneously with the changes in the temperatures. If we increase the number of simulations in 2004 and in 2005, prices will get close to the observed ones but the spikes will not be suppressed (even for 5,000 simulations or more). We need to smooth the temperatures. Results for a 7 day smoothing are shown in Fig.9. We remark that this operation gives prices which are closer to the observed ones. If we smooth more, we risk to underestimate the prices since they depend on the level of the observed temperatures. 


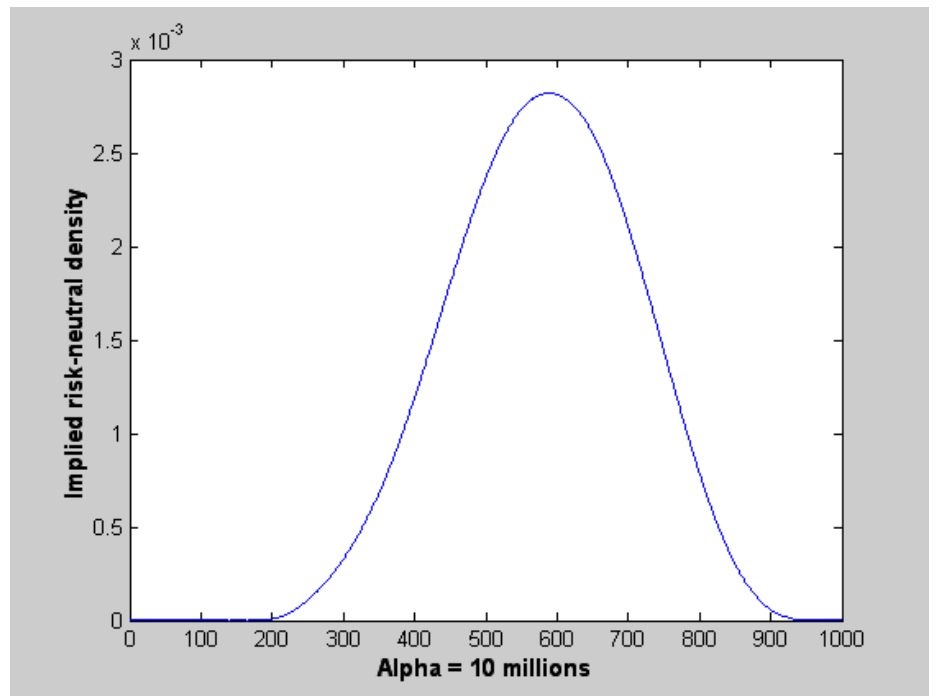

Fig.7 Implied risk-neutral density for 1000 simulations and $\alpha=10$ millions

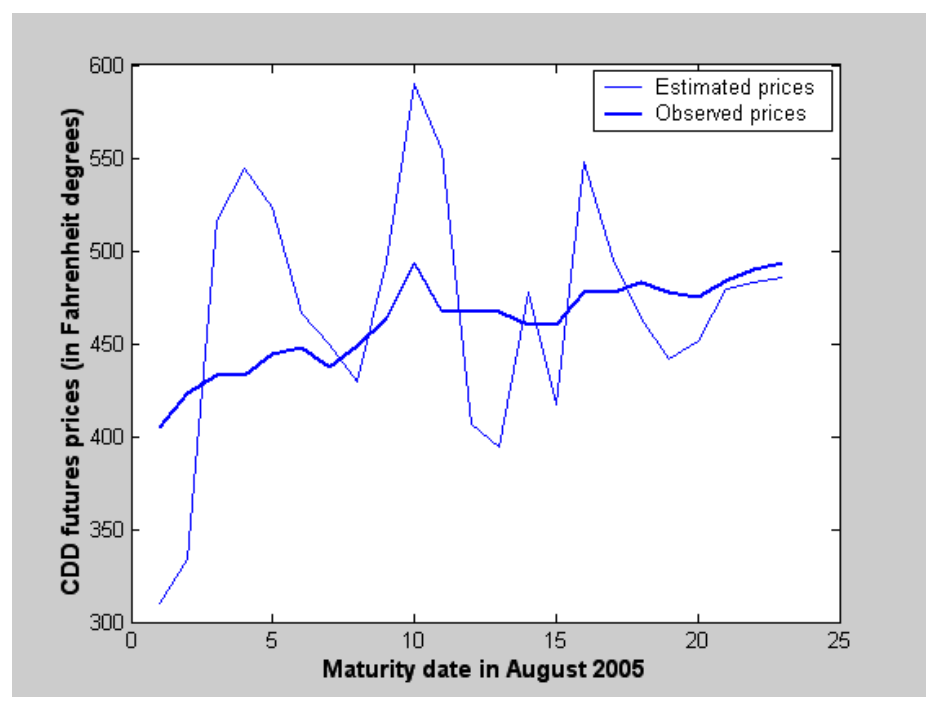

Fig.8 Observed and forecasted prices of the New York CDD futures in August 2005 with implied risk-neutral density for 1000 simulations and $\alpha=10$ millions 


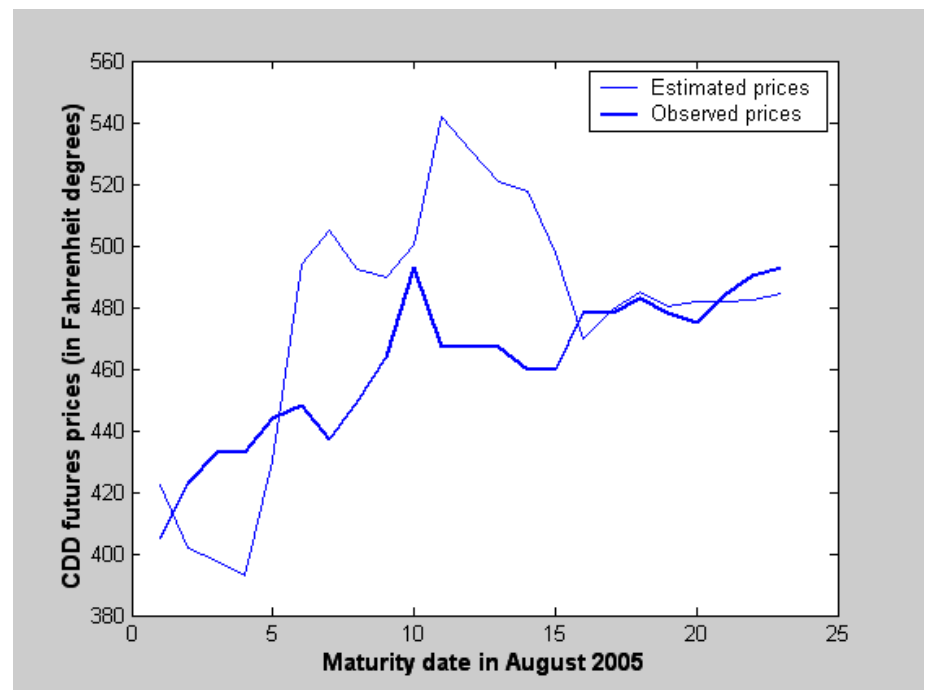

Fig.9 Observed and forecased prices of the New York CDD futures in August 2005 with implied risk-neutral density for 1000 simulations, $\alpha=10$ millions and 7 day smoothing temperatures

The estimated prices in Fig. 9 are quite precise for days close to the maturity date but are very above the observed ones for days in the middle of the contract period.

In Fig.10, we plot the estimated New York weather option prices with maturity date in August 2005 by using the implied risk-neutral density for the same period as the weather futures.

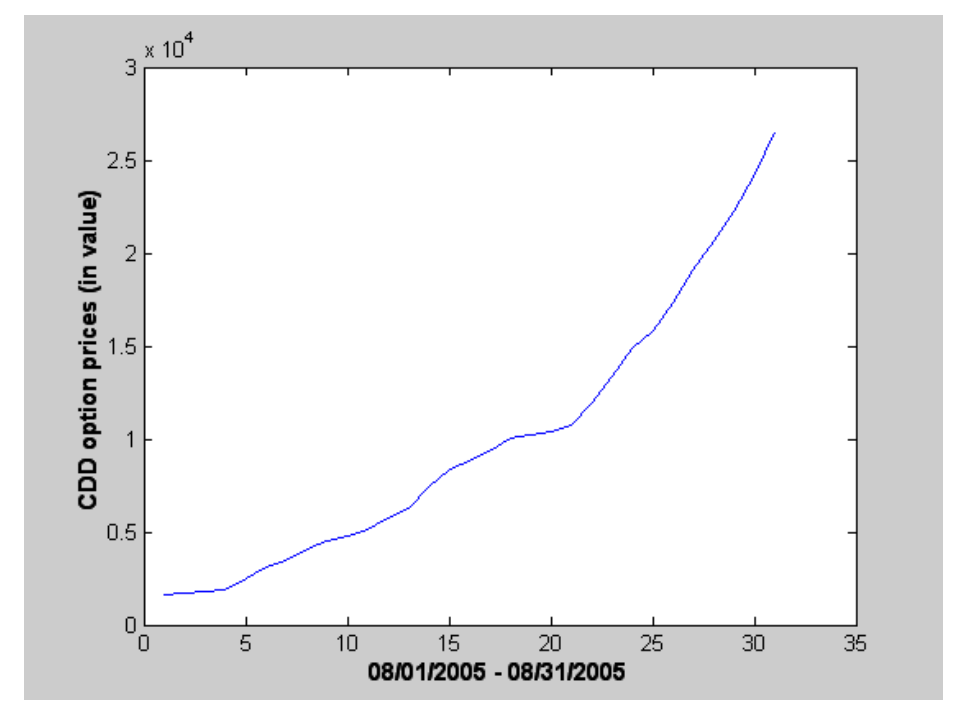

Fig.10 Estimated New York CDD call option prices with $\mathrm{r}=1 / 12$, tick $=100 \$$ and strike $=200$ 


\section{Weather derivatives and implied market price of risk}

Pirrong and Jermakyan (2001) suggest to price the electricity and weather options by extracting the market price of risk from the forward prices. Because electricity is not a storable good, non-hedgeable risks have to be faced with. Thus a market price of risk is required to price electricity derivatives. It is also required for the weather derivatives because the underlying is not a traded asset. In both cases, the market is incomplete. In this setting, the market price of risk is not equal to zero and it is defined as

$$
\lambda=\frac{\mu-r}{\sigma}
$$

for a process of the following form

$$
\frac{\mathrm{dS}}{\mathrm{S}}=\mu \mathrm{dt}+\sigma \mathrm{dW}
$$

where $r$ is the riskless interest rate and $\mu$ and $\sigma$ are respectively the drift and the volatility of the process $\mathrm{S}$.

We point out that only the market price of weather risk must be considered. We will not add any market price of risk for the jump component in the temperature process because like Merton (1976) we make the assumption that this jump component represents a nonsystematic risk and can be diversified away. This supposition is plausible since the jump component is not linked with the evolution of the financial market and it does not constitute a frequent event. We will not either introduce any market price of risk for the volatility because this latter is deterministic (see Kallsen and Taqqu (1998) for the demonstration of the completeness of the market in presence of a $\operatorname{GARCH}(1,1)$ process in continuous time).

To extract the market price of risk $\lambda$ from the prices with the Pirrong and Jermakyan (2001)'s method, the optimization problem (42) must be solved with the market prices of risk as the unknowns and the theoretical price which is the solution of a partial differential equation. For instance, the price $\mathrm{C}(\mathrm{S}, \mathrm{t})$ of an option on the asset $\mathrm{S}$ is the solution of the following PDE in an incomplete market (under the martingale measure $\mathrm{Q}$ ) :

$$
\frac{\partial \mathrm{C}}{\partial \mathrm{t}}+\frac{1}{2} \sigma^{2} \mathrm{~S}^{2} \frac{\partial^{2} \mathrm{C}}{\partial \mathrm{S}^{2}}+(\mu-\lambda \sigma) \mathrm{S} \frac{\partial \mathrm{C}}{\partial \mathrm{S}}-\mathrm{rC}=0 .
$$

PDE resolution by a numerical method is often used to calculate the price of the derivatives which do not have a closed-form expression for their value. Pirrong and Jermakyan (2001) solve the PDE by using a finite difference approach. It consists in constructing a grid of equally spaced points and in discretizing the continuous derivatives of the PDE by using difference formulas which can be forward, backward or central difference. These formulas lead to different resolution schemes which are explicit, implicit and semi-implicit (CrankNicolson) methods. Pirrong and Jermakyan (2001) implemented this method in the case of the electricity options. We will apply it in the case of the weather derivatives. The authors assume that the market price of risk is function of time and load (or electricity demand). This leads to a vastly underdetermined optimization problem because the market prices of risk must be found for each couple of time and load in the grid while we have most of the time only one observed price for each day. Like in part 5.1, a regularizer must be introduced to obtain an unique solution. But optimization problem with both a regularizer and a PDE to solve is very computational intensive (see Lagnado and Osher (1997)). We will not apply this method 
because the resolution of our PDE requires already an important computational effort because of the presence of the jump component in the temperature process and of the cumulative degree-days which imply the resolution of the PDE in two dimensions. This point will be discussed in part 6.1. To avoid adding a regularizer to the optimization problem, we assume that the market price of weather risk depends only on time and not on the temperature evolution. But this assumption does not circumvent the problem. There are still more unknowns than quoted prices because these latters are only available 5 day weeks while the market price of risk will be calculated for every day in the grid. To address this underdetermination, we assume that prices are equal to the previous available prices for days for which we have no quotation. We can make this assumption since the weather futures prices are not very volatile. Now the number of unknowns corresponds to the number of the quotes. We can solve the problem without introducing a regularizer.

\subsection{Solving the PIDE}

Since there exists no explicit form for the Eq.(9), Eq.(10), Eq.(13) and Eq.(14), we must solve a partial differential equation to calculate the price of the weather derivatives. The FeynmanKac theorem allows us to write this PDE which is in our case a PIDE (partial integrodifferential equation) because the temperature obeys a jump process.

The statement of the Feynman-Kac theorem is as follows :

for any variable $\mathrm{S}$ determined by a stochastic differential equation of the form

$$
\mathrm{dS}_{\mathrm{t}}=\mu\left(\mathrm{S}_{\mathrm{t}}, \mathrm{t}\right) \mathrm{dt}+\sigma\left(\mathrm{S}_{\mathrm{t}}, \mathrm{t}\right) \mathrm{dW}_{\mathrm{t}}+\mathrm{Udq}_{\mathrm{t}}
$$

where $\mathrm{U}$ is the jump size and $\gamma$ is the intensity of the Poisson process

and any variable

$$
\mathrm{I}_{\mathrm{t}}=\int_{0}^{\mathrm{t}} \mathrm{z}\left(\mathrm{S}_{\mathrm{s}}\right) \mathrm{ds},
$$

the solution, $\mathrm{C}\left(\mathrm{S}_{\mathrm{t}}, \mathrm{I}_{\mathrm{t}}, \mathrm{t}\right)$, to the expression

$$
E_{t}\left[e^{-\int_{0}^{t_{n}} r d v} g\left(S_{t_{n}}, I_{t_{n}}, t_{n}\right)\right]
$$

where $t_{n}>t$, is determined by the equation

$\frac{\partial \mathrm{C}}{\partial \mathrm{t}}+\frac{1}{2} \sigma\left(\mathrm{S}_{\mathrm{t}}, \mathrm{t}\right)^{2} \frac{\partial^{2} \mathrm{C}}{\partial \mathrm{S}^{2}}+\left(\mu\left(\mathrm{S}_{\mathrm{t}}, \mathrm{t}\right)-\lambda\left(\mathrm{S}_{\mathrm{t}}, \mathrm{t}\right) \sigma\left(\mathrm{S}_{\mathrm{t}}, \mathrm{t}\right)\right) \frac{\partial \mathrm{C}}{\partial \mathrm{S}}+\mathrm{z}\left(\mathrm{S}_{\mathrm{t}}\right) \frac{\partial \mathrm{C}}{\partial \mathrm{I}}+\gamma \mathrm{E}\left[\mathrm{C}\left(\mathrm{S}_{\mathrm{t}}+\mathrm{U}, \mathrm{I}_{\mathrm{t}}, \mathrm{t}\right)-\mathrm{C}\left(\mathrm{S}_{\mathrm{t}}, \mathrm{I}_{\mathrm{t}}, \mathrm{t}\right)\right]$

$=\mathrm{rC}\left(\mathrm{S}_{\mathrm{t}}, \mathrm{I}_{\mathrm{t}}, \mathrm{t}\right)$.

where the terminal condition is given by

$$
C\left(S_{t_{n}}, I_{t_{n}}, t_{n}\right)=g\left(S_{t_{n}}, I_{t_{n}}, t_{n}\right) .
$$

The PIDE obtained is in two dimensions because of the additional term $\mathrm{I}_{\mathrm{t}}$. In our case, we have for the CDD weather option price $C\left(T_{t}, I_{n}^{C}, t\right)$ : 
$\frac{\partial \mathrm{C}}{\partial \mathrm{t}}+\frac{1}{2} \sigma_{\mathrm{t}}^{2} \frac{\partial^{2} \mathrm{C}}{\partial \mathrm{T}^{2}}+\left(\frac{\mathrm{dT}_{\mathrm{t}}^{\mathrm{m}}}{\mathrm{dt}}+\mathrm{a}\left(\mathrm{T}_{\mathrm{t}}^{\mathrm{m}}-\mathrm{T}_{\mathrm{t}}\right)-\lambda_{\mathrm{t}} \sigma_{\mathrm{t}}-\gamma \mu_{\mathrm{U}}\right) \frac{\partial \mathrm{C}}{\partial \mathrm{T}}+\mathrm{z}\left(\mathrm{T}_{\mathrm{t}}\right) \frac{\partial \mathrm{C}}{\partial \mathrm{I}_{\mathrm{n}}^{\mathrm{C}}}+\gamma \mathrm{E}\left[\mathrm{C}\left(\mathrm{T}_{\mathrm{t}}+\mathrm{U}, \mathrm{I}_{\mathrm{n}}^{\mathrm{C}}, \mathrm{t}\right)\right.$

$\left.-C\left(T_{t}, I_{n}^{C}, t\right)\right]=r C\left(T_{t}, I_{n}^{C}, t\right)$

where $z\left(T_{t}\right)=\max \left(T_{t}-65,0\right)$

with terminal condition

$$
C\left(T_{t_{n}}, I_{n}^{C}, t_{n}\right)=\max \left(I_{n}^{C}-K, 0\right) \text { for a call option }
$$

where $t_{n}$ is the expiration date and $\mathrm{K}$ is the strike price.

For the CDD weather futures price $F\left(T_{t}, I_{n}^{C}, t\right)$, the PIDE is given by

$\frac{\partial \mathrm{F}}{\partial \mathrm{t}}+\frac{1}{2} \sigma_{\mathrm{t}}^{2} \frac{\partial^{2} \mathrm{~F}}{\partial \mathrm{T}^{2}}+\left(\frac{\mathrm{dT} \mathrm{T}_{\mathrm{t}}^{\mathrm{m}}}{\mathrm{dt}}+\mathrm{a}\left(\mathrm{T}_{\mathrm{t}}^{\mathrm{m}}-\mathrm{T}_{\mathrm{t}}\right)-\lambda_{\mathrm{t}} \sigma_{\mathrm{t}}-\gamma \mu_{\mathrm{U}}\right) \frac{\partial \mathrm{F}}{\partial \mathrm{T}}+\mathrm{z}\left(\mathrm{T}_{\mathrm{t}}\right) \frac{\partial \mathrm{F}}{\partial \mathrm{I}_{\mathrm{n}}^{\mathrm{C}}}+\gamma \mathrm{E}\left[\mathrm{F}\left(\mathrm{T}_{\mathrm{t}}+\mathrm{U}, \mathrm{I}_{\mathrm{n}}^{\mathrm{C}}, \mathrm{t}\right)\right.$

$\left.-F\left(T_{t}, I_{n}^{C}, t\right)\right]=0$

with terminal condition

$$
\mathrm{F}\left(\mathrm{T}_{\mathrm{t}_{\mathrm{n}}}, \mathrm{I}_{\mathrm{n}}^{\mathrm{C}}, \mathrm{t}_{\mathrm{n}}\right)=\mathrm{I}_{\mathrm{n}}^{\mathrm{C}}
$$

Note that we must add the term $\gamma \mu_{U}$ to turn the discounted temperature process in Eq.(17) into a martingale under the equivalent probability $\mathrm{Q}$.

These equations can be rewritten as

$\frac{\partial \mathrm{C}}{\partial \mathrm{t}}+\frac{1}{2} \sigma_{\mathrm{t}}^{2} \frac{\partial^{2} \mathrm{C}}{\partial \mathrm{T}^{2}}+\left(\frac{\mathrm{dT}_{\mathrm{t}}^{\mathrm{m}}}{\mathrm{dt}}+\mathrm{a}\left(\mathrm{T}_{\mathrm{t}}^{\mathrm{m}}-\mathrm{T}_{\mathrm{t}}\right)-\lambda_{\mathrm{t}} \sigma_{\mathrm{t}}-\gamma \mu_{\mathrm{U}}\right) \frac{\partial \mathrm{C}}{\partial \mathrm{T}}+\mathrm{z}\left(\mathrm{T}_{\mathrm{t}}\right) \frac{\partial \mathrm{C}}{\partial \mathrm{I}_{\mathrm{n}}^{\mathrm{C}}}+\gamma \int_{\mathrm{R}} \mathrm{C}\left(\mathrm{T}_{\mathrm{t}}+\mathrm{U}\right) \mathrm{f}(\mathrm{U}) \mathrm{dU}$

$=(\mathrm{r}+\gamma) \mathrm{C}\left(\mathrm{T}_{\mathrm{t}}, \mathrm{I}_{\mathrm{n}}^{\mathrm{C}}, \mathrm{t}\right)$

and

$\frac{\partial \mathrm{F}}{\partial \mathrm{t}}+\frac{1}{2} \sigma_{\mathrm{t}}^{2} \frac{\partial^{2} \mathrm{~F}}{\partial \mathrm{T}^{2}}+\left(\frac{\mathrm{dT}_{\mathrm{t}}^{\mathrm{m}}}{\mathrm{dt}}+\mathrm{a}\left(\mathrm{T}_{\mathrm{t}}^{\mathrm{m}}-\mathrm{T}_{\mathrm{t}}\right)-\lambda_{\mathrm{t}} \sigma_{\mathrm{t}}-\gamma \mu_{\mathrm{U}}\right) \frac{\partial \mathrm{F}}{\partial \mathrm{T}}+\mathrm{z}\left(\mathrm{T}_{\mathrm{t}}\right) \frac{\partial \mathrm{F}}{\partial \mathrm{I}_{\mathrm{n}}^{\mathrm{C}}}+\gamma \int_{\mathrm{R}} \mathrm{F}\left(\mathrm{T}_{\mathrm{t}}+\mathrm{U}\right) \mathrm{f}(\mathrm{U}) \mathrm{dU}$

$=\gamma \mathrm{F}\left(\mathrm{T}_{\mathrm{t}}, \mathrm{I}_{\mathrm{n}}^{\mathrm{C}}, \mathrm{t}\right)$

where $f(U)$ is the density function of the jump size $U$. It is given by

$$
f(x)=\frac{1}{\sigma_{x} \sqrt{2 \pi}} \exp \left[-\frac{1}{2}\left(\frac{x-\mu_{x}}{\sigma_{x}}\right)^{2}\right]
$$

since we have assumed that U was normally distributed. 
These PIDE including the convective terms $z\left(T_{t}\right) \frac{\partial C}{\partial I_{n}^{C}}$ and $z\left(T_{t}\right) \frac{\partial F}{\partial I_{n}^{C}}$ are in general difficult to solve with the finite difference approach because of the absence of the equivalent diffusive term, that is to say $\frac{\partial^{2} \mathrm{C}}{\partial\left(I_{n}^{\mathrm{C}}\right)^{2}}$ or $\frac{\partial^{2} \mathrm{~F}}{\partial\left(\mathrm{I}_{\mathrm{n}}^{\mathrm{C}}\right)^{2}}$. Solutions are subject to oscillatories (Zvan, Forsyth and Vetzal (1998)). But this difficulty can be get around if we consider discretely sampled options and futures (Dewynne and Wilmott (1995), Randall and Tavella (2000)). In this case, the convective term disappears between the sampling dates. Indeed, the stochastic differential equation of $I_{t}$ is written as

$$
\mathrm{dI}_{\mathrm{t}}=\mathrm{z}\left(\mathrm{S}_{\mathrm{t}}\right) \mathrm{dt} \text {. }
$$

Then we see that $I_{t}$ is constant between sampling times. Therefore, we can solve a PIDE in two dimensions without the convective term between the sampling dates. However, a jump condition must be satisfied. Let I be a discrete running sum, i.e

$$
I_{i}=\sum_{j} S_{j}
$$

therefore we have the following jump condition

$$
\mathrm{C}\left(\mathrm{S}, \mathrm{I}_{\mathrm{i}-1}, \mathrm{t}_{\mathrm{i}}^{-}\right)=\mathrm{C}\left(\mathrm{S}, \mathrm{I}_{\mathrm{i}-1}+\mathrm{S}, \mathrm{t}_{\mathrm{i}}^{+}\right)
$$

where $t_{i}^{-}$means just before the date $i$ and $t_{i}^{+}$for just after the date $i$. Because there is no arbitrage opportunity, the value of the option before and after the sampling dates must be the same. This continuity restriction will induce the terminal conditions for the PIDE resolution within each sampling interval.

We adopt this method to solve the PIDE since the weather futures prices are observed daily. The convolution terms $\int_{R} C\left(T_{t}+U\right) f(U) d U$ and $\int_{R} F\left(T_{t}+U\right) f(U) d U$ are approximated by using a composite trapezoidal rule. However, we must first truncate its domain. Following Briani (2003), we choose a parameter $\varepsilon>0$ and an interval $\left[\pi_{\min }, \pi_{\max }\right]$ which limits are given by

$$
\pi_{\max }=\sqrt{-2 \sigma_{U}^{2} \ln \left(\varepsilon \sigma_{U} \sqrt{2 \pi}\right)}+\mu_{U} \text { and } \pi_{\min }=-\pi_{\max }
$$

The integral in Eq.(61) is then calculated by the application of the following formula :

$$
\int_{\mathrm{a}}^{\mathrm{b}} \mathrm{F}\left(\mathrm{T}_{\mathrm{t}}+\mathrm{U}\right) \mathrm{f}(\mathrm{U}) \mathrm{dU} \approx \frac{\pi_{\mathrm{max}}-\pi_{\min }}{2 \mathrm{~L}}\left[\mathrm{~F}_{\mathrm{T}+\mathrm{x}_{0} \mathrm{f}_{0}}+2 \sum_{l=\mathrm{x}_{1}}^{\mathrm{x}_{\mathrm{L}-1}} \mathrm{~F}_{\mathrm{T}+l} \mathrm{f}_{l}+\mathrm{F}_{\mathrm{T}+\mathrm{x}_{\mathrm{L}}} \mathrm{f}_{\mathrm{x} \mathrm{L}}\right]
$$

where $\mathrm{L}$ is the number of subintervals in $\left[\pi_{\max }, \pi_{\min }\right], \mathrm{x}_{0}=\pi_{\min }$ and $\mathrm{x}_{\mathrm{L}}=\pi_{\max }$. 
To discretize our PIDEs given by Eq.(60) and Eq.(61), we employ a forward difference for the partial derivative with respect to time and a central difference for the derivative with respect to $\mathrm{T}$ which leads to an unconditionally stable implicit scheme. Even if it is less accurate than the Crank-Nicolson scheme, it never produces oscillations in time. Harris (2003) succeeds in eliminating the oscillations displayed by the Crank-Nicolson scheme by using a downwind and a semi-Lagrangian method but none of these methods seems to give the same level of accuracy than the Crank-Nicolson scheme used alone. For Eq.(61), the obtained implicit scheme with the grid notation $\mathrm{F}_{\mathrm{i}, \mathrm{j}}^{\mathrm{k}}=\mathrm{F}\left(\mathrm{i} \Delta \mathrm{t}, \mathrm{j} \Delta \mathrm{T}, \mathrm{k} \Delta \mathrm{I}_{\mathrm{n}}^{\mathrm{C}}\right)$ where $\mathrm{i}=0, \ldots, \mathrm{N}$, $\mathrm{j}=0, \ldots, \mathrm{M}$ and $\mathrm{k}=0, \ldots, \mathrm{K}$ is as follows

$$
\begin{aligned}
& \mathrm{F}_{\mathrm{i}+1, j}^{\mathrm{k}}+\Delta \mathrm{t} \times \text { integral }_{\mathrm{i}+1, \mathrm{j}}^{\mathrm{k}}=\alpha_{\mathrm{i}, \mathrm{j}} \mathrm{F}_{\mathrm{i}, \mathrm{j}-1}^{\mathrm{k}}+\beta_{\mathrm{i}} \mathrm{F}_{\mathrm{i}, \mathrm{j}}^{\mathrm{k}}+\zeta_{\mathrm{i}, \mathrm{j}} \mathrm{F}_{\mathrm{i}, \mathrm{j}+1}^{\mathrm{k}} \\
& \alpha_{\mathrm{i}, \mathrm{j}}=\Delta \mathrm{t}\left(\left(\mu_{\mathrm{i}, \mathrm{j}}-\lambda_{\mathrm{i}} \sigma_{\mathrm{i}}-\gamma \mu_{\mathrm{U}}\right) \frac{1}{2 \Delta \mathrm{T}}-\frac{1}{2} \sigma_{\mathrm{i}}^{2} \frac{1}{\Delta \mathrm{T}^{2}}\right), \\
& \beta_{\mathrm{i}}=1+\Delta \mathrm{t}\left(\sigma_{\mathrm{i}}^{2} \frac{1}{\Delta \mathrm{T}^{2}}+\gamma\right), \\
& \zeta_{\mathrm{i}, \mathrm{j}}=-\Delta \mathrm{t}\left(\frac{1}{2} \sigma_{\mathrm{i}}^{2} \frac{1}{\Delta \mathrm{T}^{2}}+\left(\mu_{\mathrm{i}, \mathrm{j}}-\lambda_{\mathrm{i}} \sigma_{\mathrm{i}}-\gamma \mu_{\mathrm{U}}\right) \frac{1}{2 \Delta \mathrm{T}}\right),
\end{aligned}
$$

where $\mu_{i, j}=\frac{\Delta T^{m}}{\Delta t}+a\left(T^{m}-j \Delta T\right), T^{m}$ and $\sigma_{i}^{2}$ are calculated respectively with Eq.(38) and Eq.(39),

$$
\text { integral }_{\mathrm{i}+1, \mathrm{j}}^{\mathrm{k}}=\gamma \frac{\pi_{\max }-\pi_{\min }}{2 \mathrm{~L}}\left[\mathrm{~F}_{\mathrm{i}+1, \mathrm{j}+\mathrm{x}_{0}}^{\mathrm{k}} \mathrm{f}_{\mathrm{x}_{0}}+2 \sum_{l=\mathrm{x}_{1}}^{\mathrm{x}_{\mathrm{L}-1}} \mathrm{~F}_{\mathrm{i}+1, \mathrm{j}+l}^{\mathrm{k}} \mathrm{f}_{l}+\mathrm{F}_{\mathrm{i}+1, \mathrm{j}+\mathrm{x}_{\mathrm{L}}}^{\mathrm{k}} \mathrm{f}_{\mathrm{x}}\right]
$$

The terminal condition for the PIDE is

$$
F\left(T_{t_{n}}, I_{n}^{C}, t_{n}\right)=I_{n}^{C}
$$

The boundary conditions are

and

$$
\mathrm{F}\left(+\infty, \mathrm{I}_{\mathrm{n}}^{\mathrm{C}}, \mathrm{t}\right)=\mathrm{I}_{\mathrm{n}}^{\mathrm{C}, \max }
$$

$$
\mathrm{F}\left(0, \mathrm{I}_{\mathrm{n}}^{\mathrm{C}}, \mathrm{t}\right)=0
$$

We explain these boundary conditions by the fact that if $T_{t}$ reaches its maximal value $T_{\max }$ in $t$ during the summer period, it will certainly keep this value for whole the period contract since this value is very high. So the futures price at time $t$ corresponds to the maximal value of $I_{n}^{C}$. If $\mathrm{T}_{\mathrm{t}}$ reaches the minimal value 0 during the summer period, this value is so low for this period that it will take a long time for the temperature to be above the $65^{\circ} \mathrm{F}$, so the futures price at time $\mathrm{t}$ will be 0 for whole the period contract.

As we solve the PIDE backward in time, the unknowns are $\mathrm{F}_{\mathrm{i}, \mathrm{j}-1}^{\mathrm{k}}, \mathrm{F}_{\mathrm{i}, \mathrm{j}}^{\mathrm{k}}$ and $\mathrm{F}_{\mathrm{i}, \mathrm{j}+1}^{\mathrm{k}}$ and they are induced by solving the following system at each time $\mathrm{i}$ : 


$$
\mathrm{F}_{\mathrm{i}+1}+\Delta \mathrm{t} \times \text { integral }_{\mathrm{i}+1}=\mathrm{AF}_{\mathrm{i}}
$$

where $\mathrm{A}$ is a tridiagonal matrix containing the elements $\alpha_{\mathrm{i}, \mathrm{j}}, \beta_{\mathrm{i}}$ and $\zeta_{\mathrm{i}, \mathrm{j}}$. These values can be calculated by inverting the matrix A but the particular form of this matrix allows to find explicitly a LU decomposition of A where $\mathrm{L}$ is a lower triangular matrix and $\mathrm{U}$ is an upper triangular matrix. Then the resolution of a system of equations $A x=q$ where $\mathrm{x}$ is the vector of unknowns reduces to solving two simpler systems $L y=q$ and $U x=y$. The number of computations is here less important than in the case of the inversion of A (see Wilmott, Dewynne and Howison (2000)).

\subsection{Results}

To solve the PDE, we construct a grid of size $200 \times 200 \times 31$. The maximal and minimal values for the temperature are respectively $100^{\circ} \mathrm{F}$ and $0^{\circ} \mathrm{F}$ with a step size of 0.4 which represents 200 intervals in the grid. The CDD index must have the same number of intervals as the temperature. So we attribute it the maximal and minimal values of 600 and 0 with a step size of 3. As their step size is different, the value $I_{n}^{C}+\max (T-65,0)$ will not correspond to the values of $I_{n}^{C}$ in the grid, so we must use interpolation to have the jump condition verified. A linear interpolation is used here. For the time variable, we have 31 intervals in the grid which corresponds to the number of days of the contract. In Fig.11, we represent the payoff of the New York CDD futures at the expiration date and in Fig.12 we plot the estimated market prices of weather risk for the New York CDD futures with maturity date in August 2004.

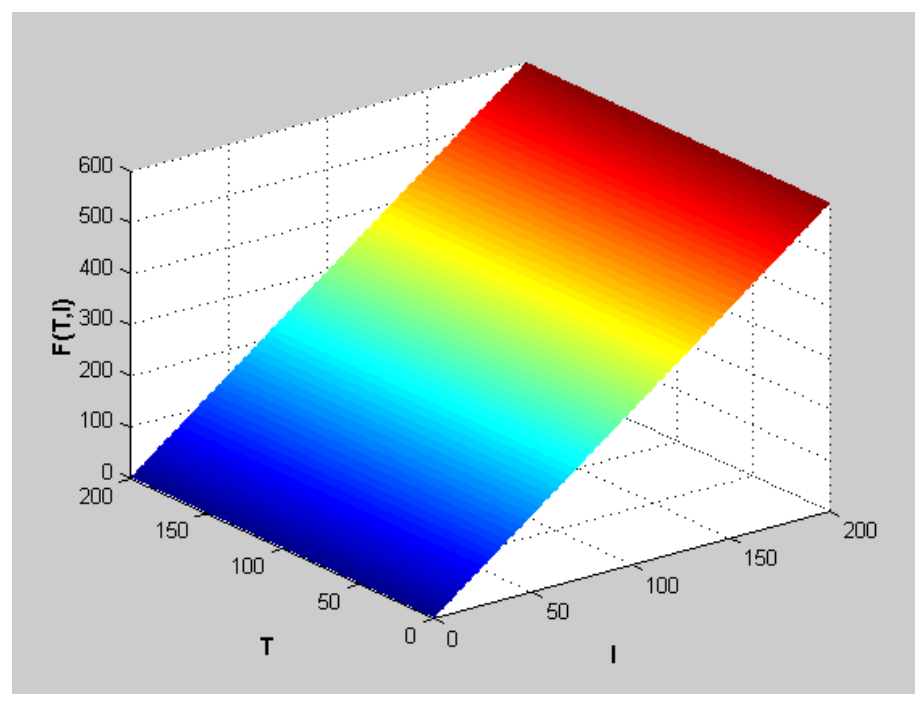

Fig.11 Value of the New York CDD futures at maturity as a function of both average temperature (T) and CDD index (I) 


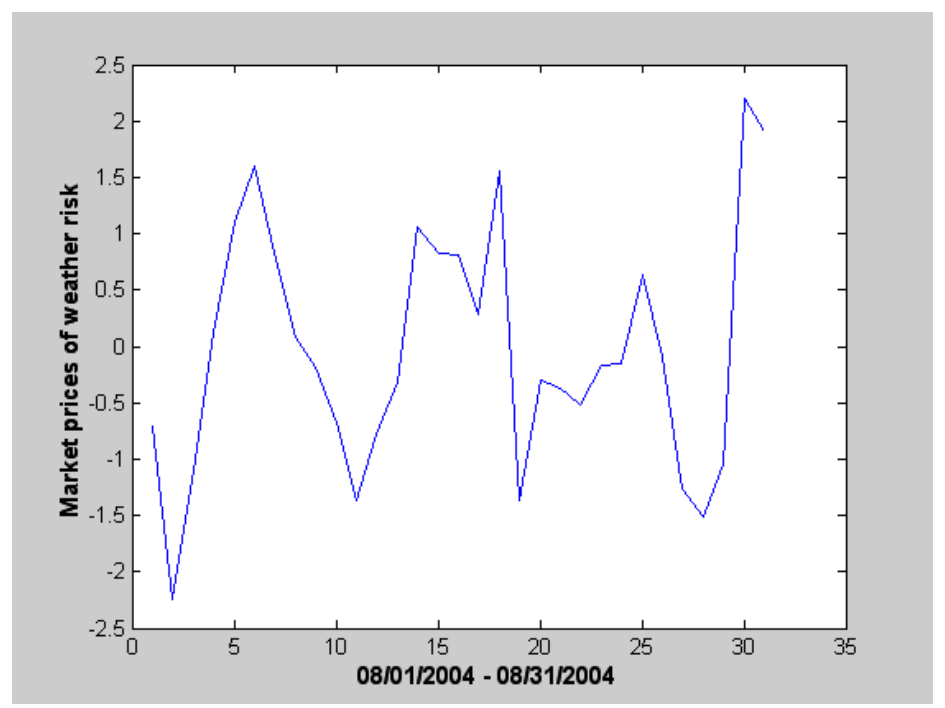

Fig.12 Implied market prices of weather risk from the New York CDD futures with maturity date in August 2004

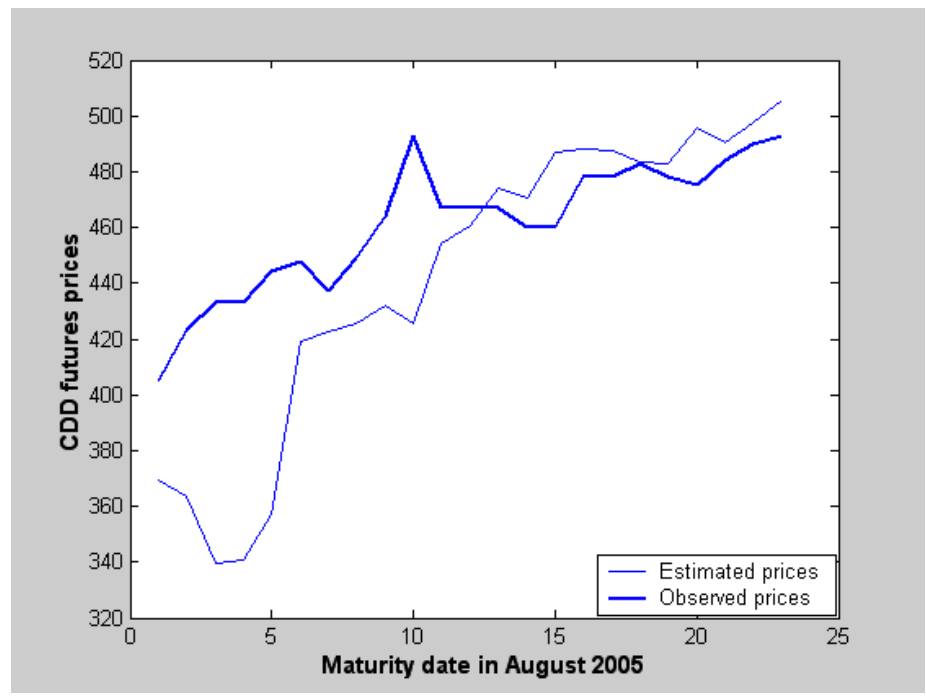

Fig.13 Observed and forecasted prices of the New York CDD futures for August 2005 with the implied market prices of weather risk from the August 2004 contract

We see in Fig. 13 that the estimated prices for dates in the middle of the contract period are much closer to the observed ones than those in Fig.9 while prices at the beginning of the contract period are still underestimated. Note that temperatures are also smoothed here by using a 7 day smoothing to suppress the spikes of the estimated prices.

In Fig.14, 15 and 16, we represent the value of the New York CDD call option with maturity date in August 2005 by using the inferred market prices of risk from the August 2004 contract shown in Fig. 12. 


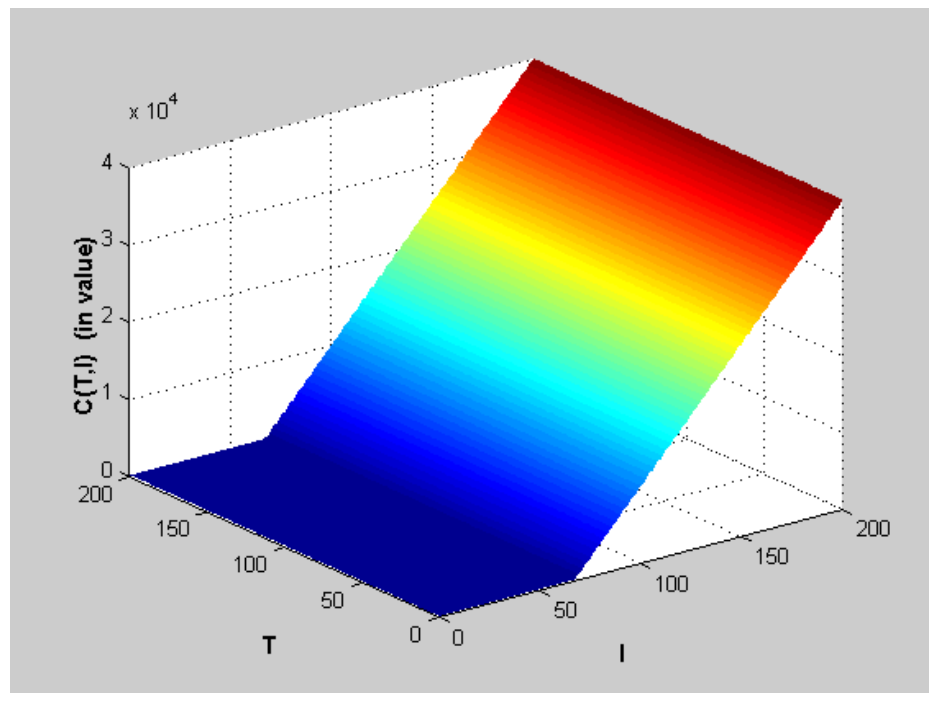

Fig.14 Value of the New York CDD call option for August 2005 at maturity with $\mathrm{r}=1 / 2$, tick $=100 \$$ and strike $=200$

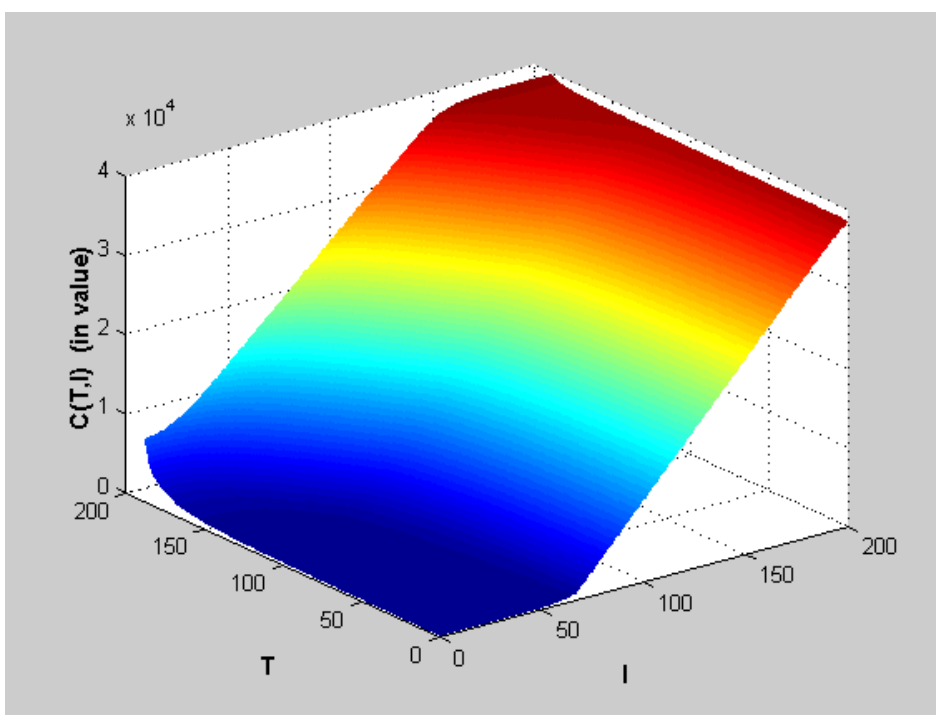

Fig.15 Value of the New York CDD call option for August 2005 at 6 days before maturity with $\mathrm{r}=1 / 2$, tick $=100 \$$ and strike $=200$ (the surface was truncated to preserve scaling) 


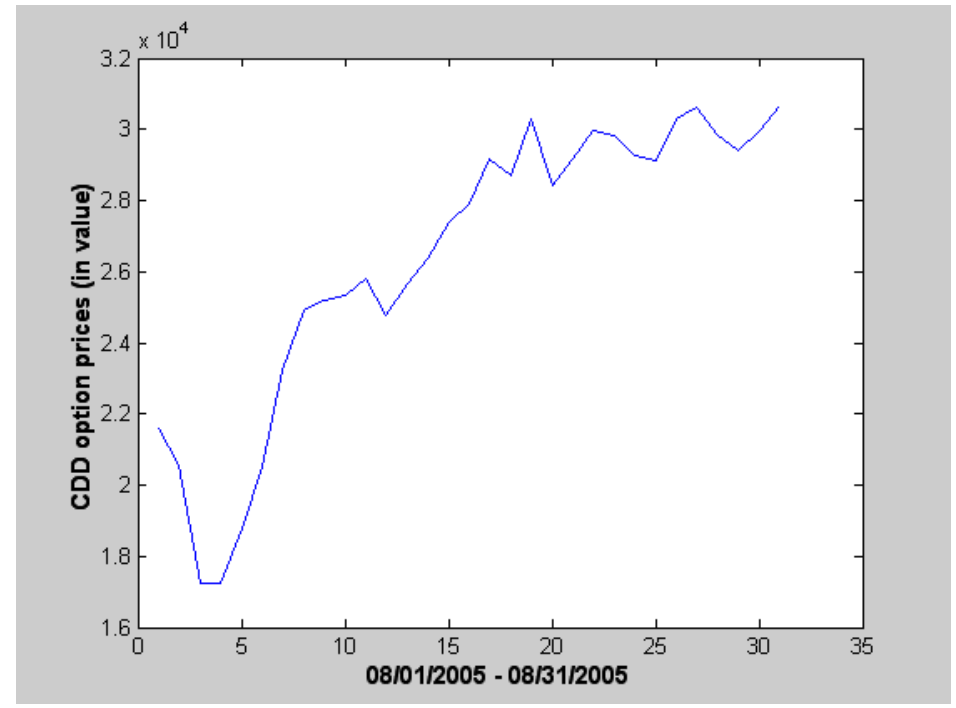

Fig.16 Estimated New York CDD call option prices for August 2005 with $\mathrm{r}=1 / 12$, tick $=100 \$$ and strike $=200$

We notice that the New York option prices in Fig.16 are very different from those in Fig.10. Prices are here higher.

\subsection{Results with information inferred from other weather contracts}

We suppose here that there is no equivalent weather futures on the CME for the New York weather option. We show in this part that we can however price it by using weather futures based on temperatures which are correlated to the New York ones. We choose the Philadelphia contract which quotations are available on the CME and which location is the nearest to the New York city. This contract is less liquid than the New York one (the traded volume is less important than the New York one). We could choose the Chicago contract but quotations for the maturity date in August 2004 starting at half of the contract period prevented us from conducting the empirical study. We show in Fig.17 that the temperatures between New York and Philadelphia are very correlated. Their correlation coefficient is 0.98 . We assume that the Philadelphia average temperatures follow also a mean-reverting jumpEGARCH process and we estimate it by employing the same method as in part 3.2. Next we extract the market prices of weather risk from the Philadelphia futures prices to value the New York futures and option with maturity date in August 2005. 


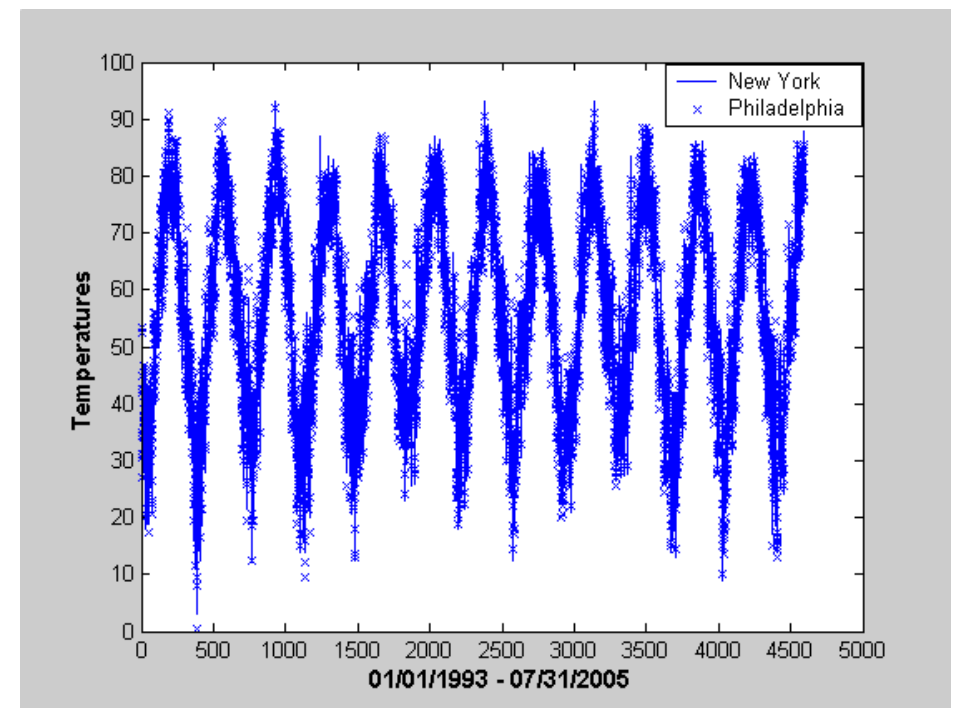

Fig.17 Daily average temperatures at LaGuardia and International Airports

We select $\mathrm{N}=8$ which gives the smallest $\mathrm{s}$. The estimated average temperature process for Philadelphia is then given by

$$
\begin{gathered}
\mathrm{dT}_{\mathrm{t}}^{\mathrm{p}}=\left[\frac{\mathrm{dT}_{\mathrm{t}}^{\mathrm{m}, \mathrm{p}}}{\mathrm{dt}}+0.30\left(\mathrm{~T}_{\mathrm{t}}^{\mathrm{m}, \mathrm{p}}-\mathrm{T}_{\mathrm{t}}^{\mathrm{p}}\right)\right] \mathrm{dt}+\sigma_{\mathrm{t}}^{\mathrm{p}} \mathrm{dW}_{\mathrm{t}}+\mathrm{U}^{\mathrm{p}} \mathrm{dq}_{\mathrm{t}}, \\
\hat{\mathrm{T}}_{\mathrm{t}}^{\mathrm{m}, \mathrm{p}}=56.43-1.57 \times 10^{-4} \mathrm{t}+22.42 \sin \left(\frac{2 \pi}{365} \mathrm{t}-2\right) \\
\ln \left(\hat{\sigma}_{\mathrm{t}}^{\mathrm{p}}\right)^{2}=-0.071+0.130\left|\frac{\Delta \hat{\varepsilon}_{\mathrm{t}-1}^{\mathrm{p}}}{\hat{\sigma}_{\mathrm{t}-1}^{\mathrm{p}}}\right|+0.030\left(\frac{\Delta \hat{\varepsilon}_{\mathrm{t}-1}^{\mathrm{p}}}{\hat{\sigma}_{\mathrm{t}-1}^{\mathrm{p}}}\right)+0.985 \ln \left(\hat{\sigma}_{\mathrm{t}-1}^{\mathrm{p}}\right)^{2}, \\
\mathrm{U}^{\mathrm{p}} \sim N(-0.27,12.87) \text { and } \hat{\gamma}^{\mathrm{p}}=0.36 .
\end{gathered}
$$




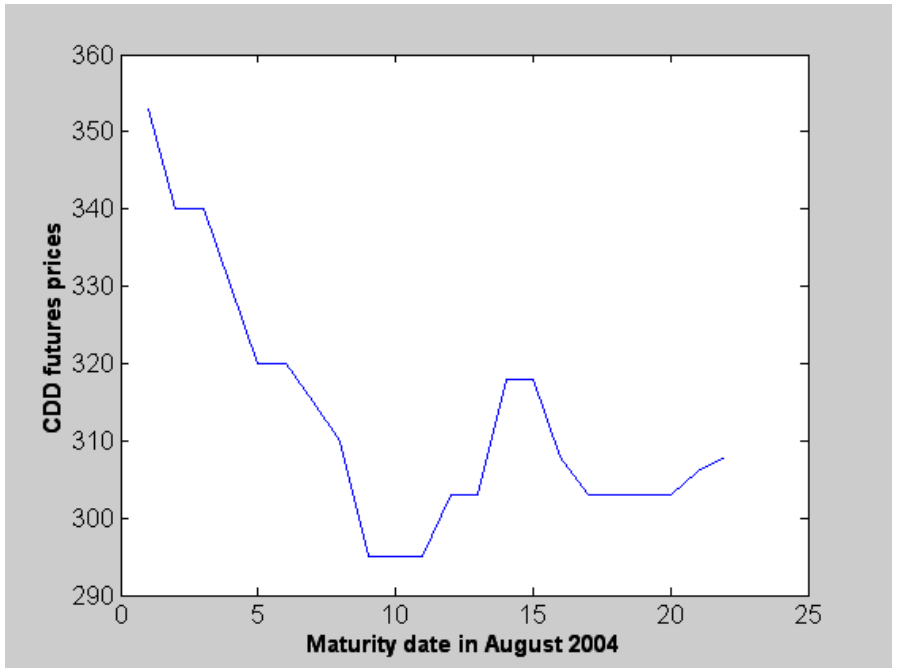

Fig.18 Philadelphia CDD futures quotations with expiration date in August 2004

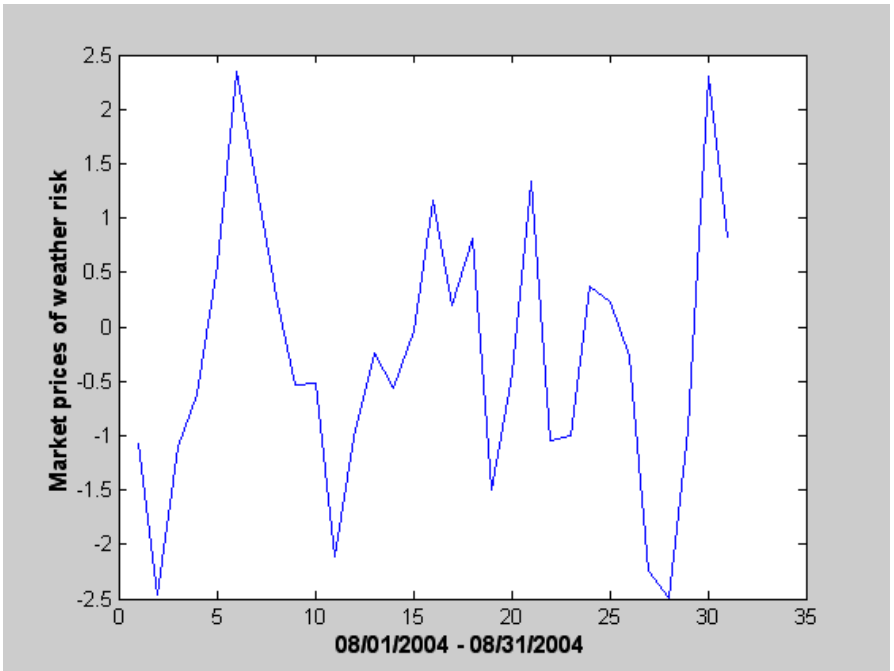

Fig.19 Estimated market prices of weather risk for the Philadelphia CDD futures with maturity date in August 2004 


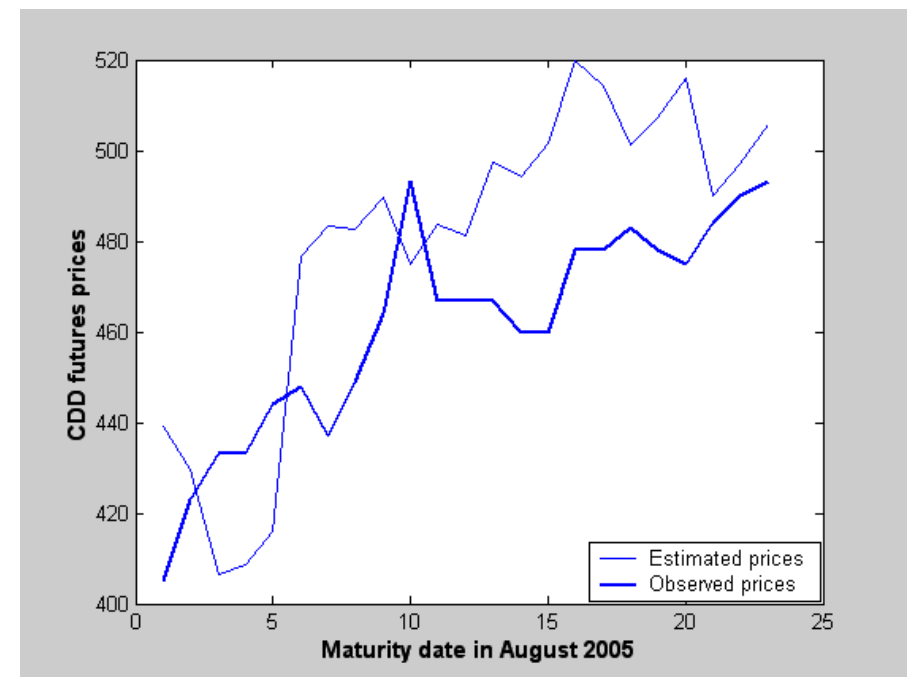

Fig.20 Observed and forecasted prices of the New York CDD futures for August 2005 with the estimated market prices of weather risk from Philadelphia contracts

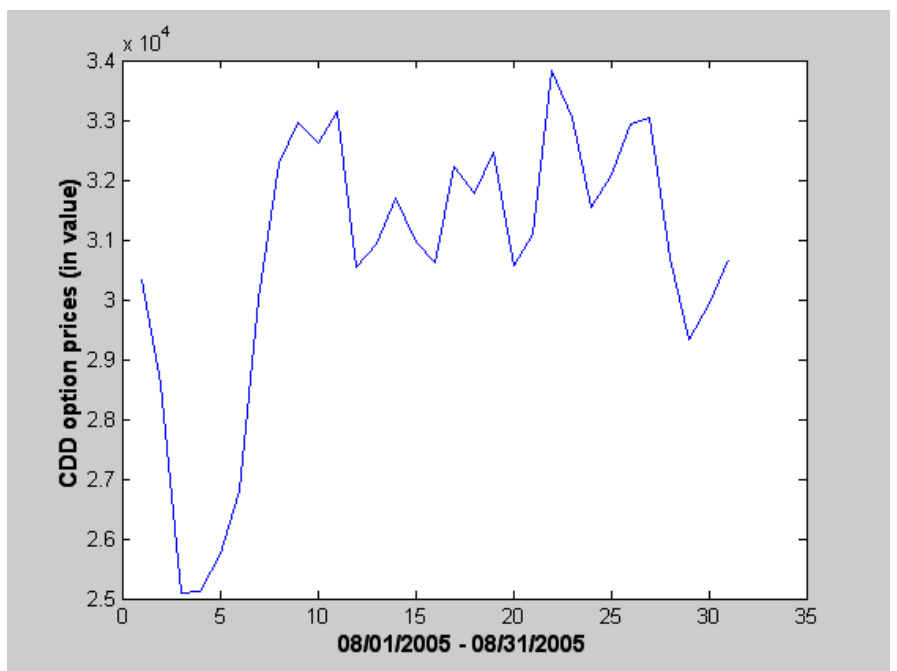

Fig.21 New York CDD call option prices for August 2005 by using the estimated market prices of weather risk from Philadelphia contracts with $\mathrm{r}=1 / 12$, tick $=100 \$$ and strike $=200$

New York futures prices in Fig.20 derived from the Philadelphia futures prices are higher than those in Fig.13. Despite this fact, the method presented here can constitute a good alternative to the problem of missing data for the equivalent weather futures since the difference between the estimated and the observed prices are not very important. This part tends to show that it is not necessary to have the equivalent contract on the CME to extract the information needed to price the weather derivatives. However we have to keep in mind that the estimated prices will not be as accurate as those derived from an equivalent futures contract although the correlation coefficient between the average temperatures are very close to one. 


\section{Conclusion}

This paper has compared the weather futures and option prices which were calculated by using Monte-Carlo simulations on one hand and on the other, by solving the PDE. The results are quite different. Estimated weather futures prices based on Monte-Carlo simulations are more volatile than those obtained by solving the PDE. This method is however more difficult to implement. A bulk of financial mathematics, theory and techniques is required to calculate the prices. In addition, computations take much more time with this approach due to the presence of the jump component in the average temperature process and of the cumulative underlying. We have also shown that information we need to price the weather derivatives can be extracted either from the equivalent futures contract or from another weather futures on the $\mathrm{CME}$ but the results are quite different even if their underlyings are very correlated.

\section{References}

Ait-Sahalia Y. and Lo A. (2000), "Nonparametric Risk Management and Implied Risk Aversion", Journal of Econometrics, Vol.94, 9-51.

Alaton P., Djehiche B. and Stillberger D. (2002), "On Modelling and Pricing Weather Derivatives", Applied Mathematical Finance, Vol.9, 1-20.

Ball, C. and Torous W. (1985), "On Jumps in Common Stock Prices and Their Impact on Call Option Pricing”, Journal of Finance, Vol.40, 155-174.

Bahra, B. (1997), "Implied Risk-neutral Probability Density Functions from Option Prices: Theory and Application", Bank of England, Working Paper 66.

Benth F.E. and Šaltytė-Benth J. (2005), "Stochastic Modelling of Temperature Variations with a View Towards Weather Derivatives", Applied Mathematical Finance, Vol.12, No.1, 53-85.

Breeden D. and Litzenberger R. H. (1978), "Prices of state-contingent claims implicit in option prices", Journal of Business, Vol. 51, 621-651.

Briani M. (2003), "Numerical Methods for Option Pricing in Jump-diffusion Markets", Thesis, University of Rome.

Brix A., Jewson S. and Ziehmann C. (2002), "Weather Derivative Modelling and Valuation : a Statistical Perspective", in Climate Risk and the Weather Market, Financial Risk Management with Weather Hedges, ed. Dischel R.S., 127-150.

Brody D.C., Syroka J. And Zervos M. (2002), "Dynamical Pricing of Weather Derivatives", Quantitative Finance, Vol.2, 189-198.

Cummins J.D., Geman H. (1994), “An Asian Option Approach to Valuation of Insurance Futures Contracts", Review Futures Markets, Vol.13, 517-557.

Das S.R. (1998), "Poisson-Gaussian process and the bond markets", Working paper 6631, NBER. 
Dewynne J.N. and Wilmott P. (1995), "A Note on Average Rate Options with Discrete Sampling”, SIAM Journal of Applied Mathematics, Vol.55, No.1, 267-276.

Dischel B. (1999), "A Weather Risk Management Choice: Hedging with Degree-day Derivatives", in Insurance and Weather Derivatives : From Exotic Options to Exotic Underlyings, ed. H. Geman, 183-195.

Dornier F. and Queruel M. (2000), "Caution to the wind”, Weather Risk Special Report 2000, Energy \& Power Risk Management/Risk Magazine.

Duffie D. and Richardson H.R. (1991), "Mean-Variance Hedging in Continuous Time", Annals of Applied Probability, Vol.1, No.1, 1-15.

Föllmer H. and Sondermann D. (1986), "Hedging of Non-Redundant Contingent Claims", in Contributions to Mathematical Economics, eds. W. Hildenbrand and A. Mas-Colell.

Amsterdam : North-Holland, 205-223.

Frittelli M. (2000), "The Minimal Entropy Martingale Measure and the Valuation Problem in Incomplete Markets”, Mathematical Finance, Vol. 10, No.1, 39-52.

Geman H., Vasicek O. (2001), "Plugging into Electricity”, Risk, August, 93-99.

Harris C. (2003), "The Valuation of Weather Derivatives using Partial Differential Equations", Dissertation, University of Reading.

Harrison, J. M. and Pliska S. (1981), "Martingales and Stochastic Integrals in the Theory of Continuous Trading," Stochastic Processes and Their Applications, Vol.11, 215-60.

Jackwerth J.C. and Rubinstein M. (1996), "Recovering Probability Distributions from Option Prices", Journal of Finance, Vol.51, No.5, 1611-1631.

Jewson S. (2003a), "Introduction to Weather Derivative Pricing", Risk Management Solutions Inc., http://stephenjewson.com/articles/.

Jewson S. (2004b), "Weather Derivative Pricing and the Potential Accuracy of Daily Temperature Modelling”,Risk Management Solutions Inc., http://stephenjewson.com/articles/.

Kallsen J. And Taqqu M.S. (1998), "Option Pricing in ARCH-type models", Mathematical Finance, Vol.8, No.1, 13-26.

Karatzas I. And Kou G. (1996), "On the Pricing of Contingent Claims under Constraints", Annals of Applied Probability, Vol. 6, No.2, 321-369.

Lagnado R. and Osher S. (1997), "A Technique for Calibrating Derivative Security Pricing Models: Numerical Solution of an Inverse Problem", Journal of computational Finance, Vol.1, No.1, 13-25.

Marteau D., Carle J., Fourneaux S., Holz R. and Moréno M. (2004), La Gestion du Risque Climatique, Economica. 
Merton R.C. (1976), “Option Pricing When Underlying Stock Returns are Discontinuous", Journal of Financial Economics, Vol.3, 125-144.

Moréno M. (2000), "Riding the Temp", Weather Derivatives, FOW Special Supplement, December.

Müller A. and Grandi M. (2000), "Weather Derivatives : A Risk Management Tool for Weather-sensitive Industries", Geneva Papers on Risk and Insurance, Vol. 25, No.2, 273-287.

Pirrong C. And Jermakyan M. (2001), "The Price of Power : The Valuation of Power and Weather Derivatives", Working paper.

Randall C. and Tavella D. (2000), Pricing Financial Instruments - the Finite Difference Method, John Wiley \& Sons, Inc.

Richards T.J., Manfredo M.R. and Sanders D.R. (2004), "Pricing Weather Derivatives", American Journal of Agricultural Economics, Vol.4, 1005-1017.

Rouge R. and El Karoui N. (2000), "Pricing via Utility Maximization and Entropy", Mathematical Finance, Vol.10, No.2, 259-276.

Roustant O. (2002), "Une application de deux modèles économétriques de température à la gestion des risques climatiques ( ${ }^{\text {ère }}$ partie)", Banque \& Marchés, 58, 22-29.

Roustant O. (2002), "Une application de deux modèles économétriques de température à la gestion des risques climatiques ( $2^{\text {ème }}$ partie)", Banque \& Marchés, 59, 36-44.

Schweizer M. (1992), "Mean-Variance Hedging for General Claims", Annals of Applied Probability, Vol.2, No.1, 171-179.

Schweizer M.(1996), "Approximation Pricing and the Variance-Optimal Martingale Measure", Annals of Probability, Vol.24, No.1, 206-236.

Stutzer M. (1996), “A Simple Nonparametric Approach to Derivative Security Valuation”, Journal of Finance, Vol. 51, No.5, 1633-1652.

Wilmott P., Dewynne J.N. and Howison P. (2000), Option Pricing : Mathematical Models and Computation, Oxford Financial Press.

Zvan R., Forsyth P.A. and Vetzal K.R. (1998), "Robust Numerical Methods for PDE Models of Asian Options”, Journal of Computational Finance, Vol.1, No.2, 39-78. 